\title{
Phase II benchmark control problem for seismic response of cable-stayed bridges
}

\author{
J. M. Caicedo ${ }^{1}$, S. J. Dyke ${ }^{1, *, \dagger}$, S. J. Moon ${ }^{2}$, L. A. Bergman ${ }^{3}$, G. Turan ${ }^{4}$ and S. Hague ${ }^{5}$ \\ ${ }^{1}$ Department of Civil Engineering, Washington University in St Louis, St Louis, MO 63130, USA \\ ${ }^{2}$ Korea Institute of Machinery and Materials, P.O. Box 101, Yusung, Taejon 305-600, South Korea \\ ${ }^{3}$ Department of Aeronautical Engineering, University of Illinois, Urbana, IL 61801, USA \\ ${ }^{4}$ Department of Civil Engineering, Izmir Institute of Technology, Izmir, Turkey \\ ${ }^{5}$ HNTB Corporation, 715 Kirk Drive, Kansas City, MO 64105, USA
}

\begin{abstract}
SUMMARY
This paper presents the problem definition for the second generation of benchmark structural control problems for cable-stayed bridges. The goal of this study is to provide a testbed for the development of strategies for the control of cable stayed-bridges. Based on detailed drawings of the Bill Emerson Memorial Bridge, a three-dimensional evaluation model has been developed to represent the complex behavior of the full-scale benchmark bridge. Phase II considers more complex structural behavior than phase I, including multi-support and transverse excitations. Evaluation criteria are presented for the design problem that are consistent with the goals of seismic response control of a cable-stayed bridge. Control constraints are also provided to ensure that the benchmark results are representative of a control implementation on the physical structure. Each participant in this benchmark bridge control study is given the task of defining, evaluating and reporting on their proposed control strategies. Participants should also evaluate the robust stability and performance of their resulting designs through simulation with an evaluation model which includes additional mass due to snow loads. The problem and a sample control design have been made available in the form of a set of MATLAB equations. Copyright (C) 2003 John Wiley \& Sons, Ltd.
\end{abstract}

KEY WORDS: cable-stayed bridges; benchmark problem; seismic excitation

\section{INTRODUCTION}

The control of long-span bridges represents a challenging and unique problem, with many complexities in modeling, control design and implementation. Cable-stayed bridges exhibit complex behavior in which the vertical, translational and torsional motions are often strongly coupled. Clearly, the control of very flexible bridge structures has not been studied to the same extent as buildings have. As a result, little expertise has been accumulated. Thus, the control of seismically excited cable-stayed bridges presents a challenging problem to the structural control community.

\footnotetext{
*Correspondence to: S. J. Dyke, Department of Civil Engineering, Washington University in St Louis, St Louis, MO 63130, USA.

†E-mail: sdyke@seas.wustl.edu

Contract/grant sponsor: US National Science Foundation; Contract/grant number: CMS 97-33272
}

Copyright (C) 2003 John Wiley \& Sons, Ltd.

Received 16 January 2003 Revised 21 May 2003 
The first generation of benchmark problems on cable-stayed bridges focused on the Bill Emerson Memorial Bridge under construction in Cape Girardeau, Missouri, USA ([1,2]; see also: http://wusceel.cive.wustl.edu). Based on detailed drawings of the Emerson bridge, a threedimensional evaluation model was developed to represent the complex behavior of the full-scale benchmark bridge. A linear evaluation model, using the equations of motion generated around the deformed equilibrium position, was deemed appropriate. Because the structure is attached to bedrock, the effects of soil-structure interaction were neglected. To simplify the problem for phase I, two assumptions were made regarding the excitation. This problem focused on a onedimensional ground acceleration applied in the longitudinal direction and uniformly and simultaneously applied at all supports. Researchers reported their phase I results during a theme session devoted to this problem held at the 3rd World Conference on Structural Control in April 2002 in Como, Italy [3-6].

Although a significant amount of expertise was accumulated during phase I, the assumptions made regarding the excitation (longitudinal and simultaneously acting) limited the extent to which this problem modeled a realistic situation. A structure's response to an earthquake is based on the simultaneous action of three translational components of ground motion: two in the horizontal plane, and one in the vertical direction. Structures are typically analyzed for the two horizontal components of ground motion. The structural response depends on the incidence angle (the angle between the ground motion components and the structural axes). Additionally, the excitation is expected to vary at each of the supports, owing to the length of these structures. A phase II problem was developed to extend the problem to consider these issues.

This paper presents the second generation of benchmark control problems for cable-stayed bridges. In this problem the ground acceleration may be applied in any arbitrary direction, using the two horizontal components of the historical earthquake with a specified incidence angle. Multi-support excitation is also considered in this phase of the study. Here the prescribed ground motion is assumed to be identical at each support, although it is not applied simultaneously. We assume that bent 1 undergoes a specified ground motion, and the motion, at the other three supports is identical to this motion but delayed based on the distance between adjacent supports and the speed of the L-wave of a typical earthquake $(3 \mathrm{~km} / \mathrm{s})$. The total responses of the structure is obtained by superposition of the responses due to each independent support input $[7,8]$.

This problem has been prepared to provide a testbed for the development of effective strategies for the control of long-span bridges. This second-generation problem considers the control of more complex motions of the bridge as compared with the first-generation problem. To evaluate the proposed control strategies in terms that are meaningful for cable-stayed bridges, appropriate evaluation criteria and control design constraints are specified within the problem statement. Additionally, an alternate model of the bridge is developed for evaluating the robustness of the designs. This model includes the effects of snow loads on the bridge deck. Designers and researchers participating in this benchmark study will define all devices, sensors and control algorithms used, evaluate them in the context of their proposed control strategies, and report the results. These strategies may be passive, active, semi-active or a combination thereof. The phase II problem will be made available for downloading on the benchmark web site in the form of a set of MATLAB equations http://wusceel.cive.wustl.edu/quake/. A sample control design is included. 


\section{BENCHMARK CABLE-STAYED BRIDGE}

The cable-stayed bridge used for this benchmark study is the Bill Emerson Memorial Bridge spanning the Mississippi River (on Missouri 74-Illinois 146) near Cape Girardeau, Missouri, designed by the HNTB Corporation [9]. The bridge is currently under construction and is to be completed in 2003. Instrumentation is being installed in the Emerson bridge and surrounding soil during the construction process to evaluate structural behavior and seismic risk [10].

Seismic considerations were strongly considered in the design of this bridge, owing to the location of the bridge (in the New Madrid seismic zone) and its critical role as a principal crossing of the Mississippi River. In early stages of the design process, the loading case governing the design was determined to be due to seismic effects. Earthquake load combinations in accordance with American Association of State Highway and Transportation Officials (AASHTO) division I-A specifications were used in the design. Various designs were considered, including full longitudinal restraint at the tower piers, no longitudinal restraint, and passive isolation. When temperature effects were considered, it was found that fully restraining the deck in the longitudinal direction would result in unacceptably large stresses. On the basis of examination of the various designs, it was determined that incorporating force transfer devices would provide the most efficient solution.

Sixteen 6.67 MN (1500 kip) shock transmission devices are employed in the connection between the tower and the deck. These devices are installed in the longitudinal direction to allow for expansion of the deck due to temperature changes. Under dynamic loads these devices are extremely stiff and are assumed to behave as rigid links. Additionally, in the transverse direction earthquake restrainers are employed at the connection between the tower and the deck, and the deck is constrained in the vertical direction at the towers. The bearings at bent 1 and pier 4 are designed to permit longitudinal displacement and rotation about the transverse and vertical axis. Soil-structure interaction is not expected to be an issue with this bridge as the foundations of the cable-stayed portion is attached to bedrock.

As shown in Figure 1, the bridge is composed of two towers, 128 cables, and 12 additional piers in the approach bridge from the Illinois side. It has a total length of $1205.8 \mathrm{~m}(3956 \mathrm{ft})$. The main span is $350.6 \mathrm{~m}(1150 \mathrm{ft})$ in length, the side spans are $142.7 \mathrm{~m}(468 \mathrm{ft})$ in length, and the approach on the Illinois side is $570 \mathrm{~m}(1870 \mathrm{ft})$. A cross-section of the deck is shown in Figure 2. The bridge has four lanes plus two narrower bicycle lanes, for a total width of $29.3 \mathrm{~m}$ (96 ft). The deck is composed of steel beams and prestressed concrete slabs. Steel ASTM A709 grade 50 W is used, with $f_{y}=344 \mathrm{MPa}(50 \mathrm{ksi})$. The concrete slabs are made of prestressed concrete with $f_{c}^{\prime}=41.36 \mathrm{MPa}(6000 \mathrm{psi})$.

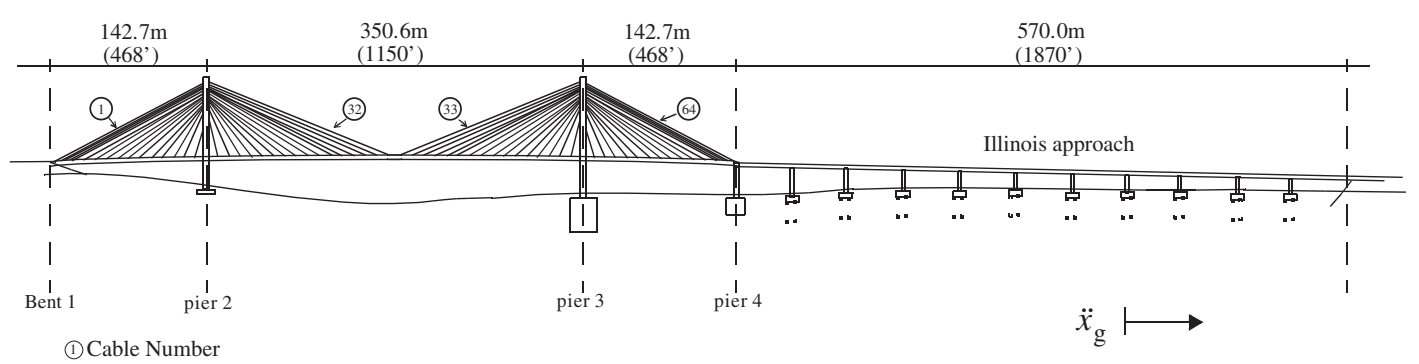

Figure 1. Drawing of the Cape Girardeau bridge. 


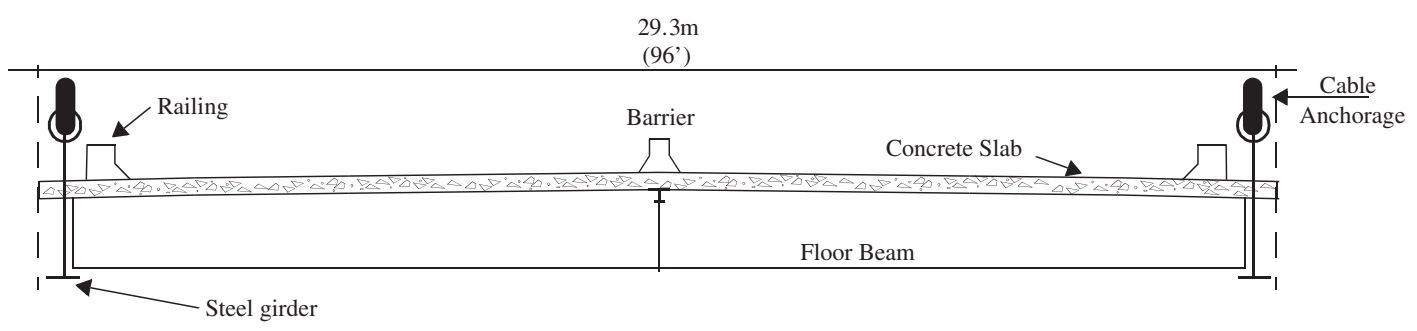

Figure 2. Cross-section of bridge deck.

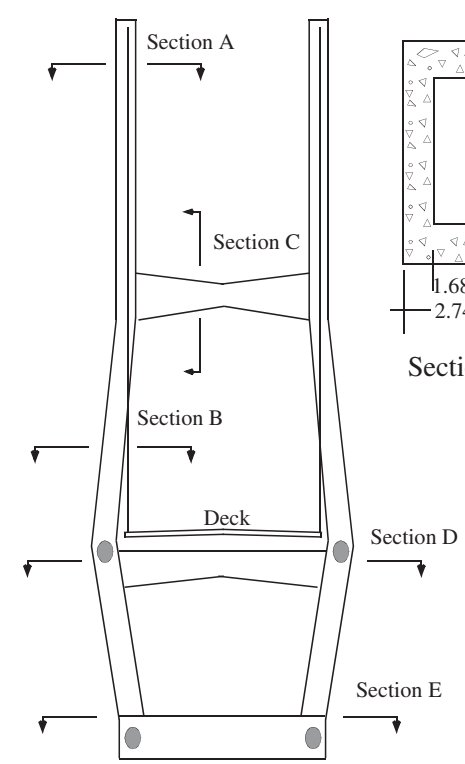

Shear force response locations

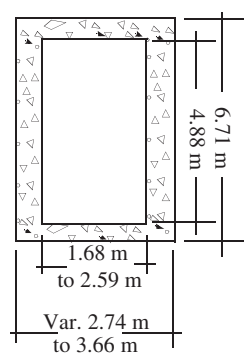

Section B

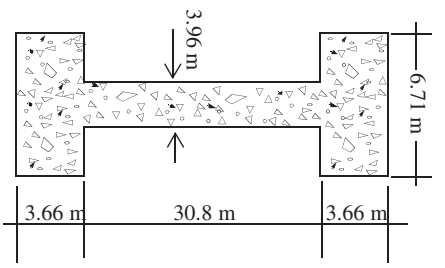

Section D

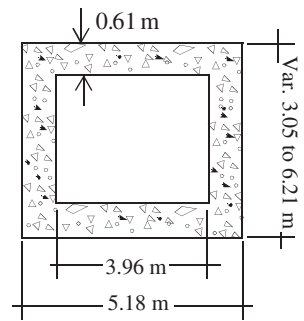

Section C

Figure 3. Cross-sections of the towers.

The 128 cables are made of high-strength, low-relaxation steel (ASTM A882 grade 270). The smallest cable area is $28.5 \mathrm{~cm}^{2}\left(4.41 \mathrm{in}^{2}\right)$ and the largest cable area is $76.3 \mathrm{~cm}^{2}\left(11.83 \mathrm{in}^{2}\right)$. The Hshaped towers have a height of $102.4 \mathrm{~m}(336 \mathrm{ft})$ at pier 2 and 108.5 (356 ft) at pier 3 (Figure 3). Each tower supports a total of 64 cables. The approach bridge from the Illinois side is supported by 11 piers and bent 15 , which are made of concrete. The deck consists of a rigid diaphragm made of steel with a slab of concrete.

\section{EVALUATION MODEL}

Based on the description of the Emerson bridge provided in the previous section, a threedimensional finite element model of the bridge was developed in MATLAB [11]. A linear evaluation model is used in this benchmark study. However, the stiffness matrices used in this 
linear model are those of the structure determined through a nonlinear static analysis corresponding to the deformed state of the bridge with dead loads [12]. Additionally, the bridge is assumed to be attached to bedrock, and the effects of soil-structure interaction are neglected. A detailed description of the finite element model development is provided elsewhere [1].

The finite element model employs beam elements, cable elements and rigid links. The nonlinear static analysis is performed in ABAQUS [13], and the element mass and stiffness matrices are output to MATLAB for assembly. Subsequently, the constraints are applied, and a reduction is performed to reduce the size of the model to something more manageable [1]. The first ten undamped frequencies of the evaluation model are $0.2899,0.3699,0.4683,0.5158$, $0.5812,0.6490,0.6687,0.6970,0.7102$, and $0.7203 \mathrm{~Hz}$.

To make it possible for designers and researchers to place devices acting longitudinally between the deck and the tower, a modified evaluation model is formed in which the tower and the deck are disconnected. If a designers on researcher specifies devices at these nodes, the second model will be formed as the evaluation model, and the control devices should connect the deck to the tower. As one would expect, the frequencies of this model are much lower than those of the nominal bridge model. The first ten undamped frequencies of this second model are $0.1619,0.2667,0.3725,0.4547,0.5017,0.5653,0.6190,0.6489,0.6968$, and $0.7097 \mathrm{~Hz}$. Note that the uncontrolled structure, used as a basis of comparison for the controlled system, corresponds to the former model in which the deck-tower connections are fixed (the dynamically stiff shock transmission devices are present).

\subsection{Description of finite element model}

The finite element model, shown in Figure 4, has a total of 579 nodes, 420 rigid links, 162 beam elements, 134 nodal masses and 128 cable elements. The towers are modelled by 50 nodes, 43 beam elements and 74 rigid links. Constraints are applied to restrict the deck from moving in the lateral direction at piers 2, 3 and 4. Boundary conditions restrict the motion at pier 1 to allow only longitudinal displacement $(X)$ and rotations about the $Y$ and $Z$ axes. Because the

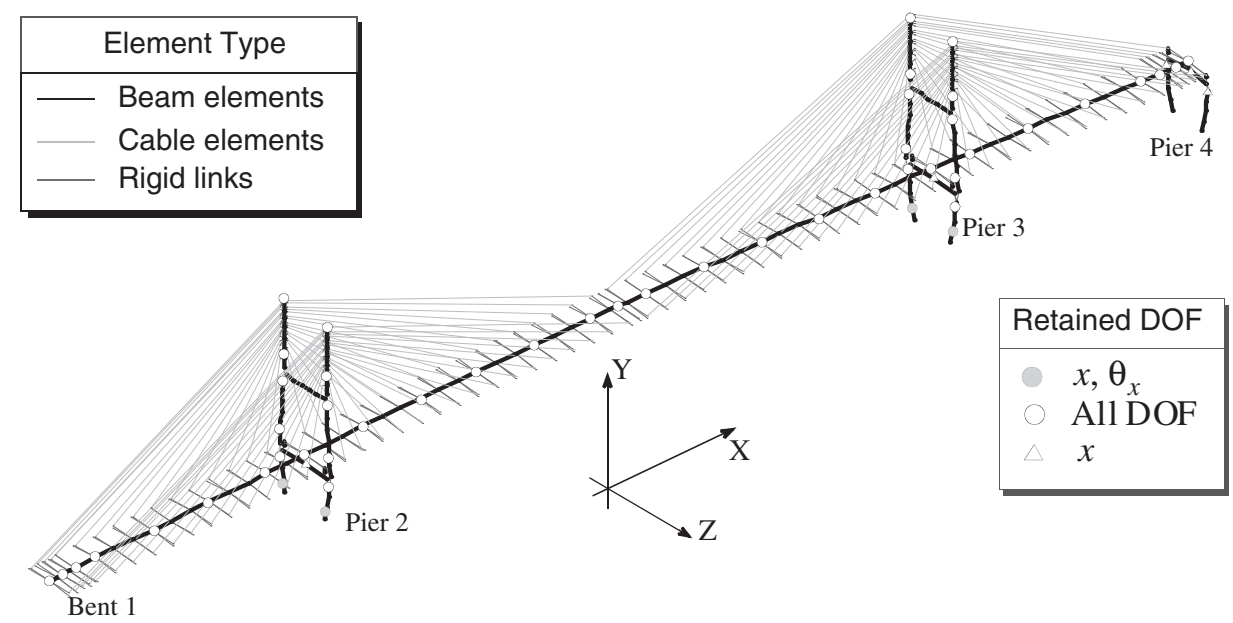

Figure 4. Finite element model. 
attachment points of the cables to the deck are above the neutral axis of the deck, and the attachment points of the cables to the tower are outside the neutral axis of the tower, rigid links are used to connect the cables to the tower and to the deck. The use of the rigid links ensures that the length and inclination angle of the cables in the model agree with the drawings. Additionally, the moment induced in the towers by the movement of the cables is taken into consideration in this approach. In the case of variable sections, the average of the section is used for the finite element. The cables are modeled with truss elements. In the finite element model the nominal tension is assigned to each cable.

This FEM model is used directly in cases when the control devices are employed in the longitudinal direction between the deck and tower. If the designer on researcher employs no control device at these locations (in which case the shock transmission devices are included), the model is modified by including four longitudinally directed, axially stiff beam elements that force the deck to move with the tower in the longitudinal direction. The uncontrolled structure used as a basis of comparison corresponds to this second case. Note that the program included with the benchmark files determines if the designer or researcher has placed devices in this location, and builds the appropriate FEM model.

Cable-stayed bridges exhibit nonlinear behavior due to variations of the catenary shape of the inclined cables, cable tensions that induce compression forces in the deck and towers, and large displacements. A nonlinear static analysis was performed, using the commercial finite element program ABAQUS, giving the model tangent stiffness matrix at the (deformed) equilibrium position. In ABAQUS, the B31 beam element was used for the structural beam element, and the element T3D2 was used for the cable elements. Further details on this procedure can be found elsewhere [1].

In modeling the cables, the catenary shape and its variation with the axial force in the cable are modeled by an equivalent elastic modulus [14]. The cable elements are modeled as truss elements in ABAQUS, and their equivalent elastic moduli are used in the nonlinear static analysis. The deck is comprised of two main steel girders along each longitudinal edge of the deck supporting the concrete slab (see Figure 2). The deck was modeled by the method described by Wilson and Gravelle [12] and is treated as a C-shaped section. In this approach the deck is modeled as a central beam (the spine) which has no mass. Lumped masses are employed to model the mass of the deck, which are connected to the spine by rigid links. The masses are included for more realistic modeling of the torsional response of the deck to lateral loads, and have been shown to be important in the modeling of this structure [15].

\subsection{Problem formulation}

Consider the general equation of motion for a structural system subjected to seismic loads

$$
\mathbf{M U ̈}+\mathbf{C} \dot{\mathbf{U}}+\mathbf{K U}=-\mathbf{M} \Gamma \ddot{x}_{\mathrm{g}}+\Lambda \mathbf{f}
$$

where $\ddot{\mathbf{U}}\left[\mathrm{m} / \mathrm{s}^{2}\right]$ is the second time derivative of the displacement response vector $\mathbf{U}[\mathrm{m}], \mathbf{M}, \mathbf{C}$, and $\mathbf{K}$ are the mass, damping and stiffness matrices of the structure, $\mathbf{f}[\mathrm{N}]$ is the vector of control force inputs, $\ddot{x}_{\mathrm{g}}\left[\mathrm{m} / \mathrm{s}^{2}\right]$ is the ground acceleration, $\Gamma$ is a vector of zeros and ones, relating the ground acceleration to the bridge degrees of freedom (DOF), and $\Lambda$ is a vector relating the force(s) produced by the control device(s) to the bridge DOFs. This equation is appropriate when the excitation has a single component or when the excitation is uniformly applied at all supports of the structure. The formulation of the equations expressing the response to multiple 
input component is somewhat different, however, from that described for the system having only a single input component. For multiple supports, the resulting motion of the supports relative to each other induces pseudo-static responses in the structure that must be considered in addition to the dynamic responses.

For the analysis of the bridge with multiple-support excitation, the model must include the degrees of freedom at the supports. The equation of dynamic equilibrium for all the DOFs is written in partitioned form $[7,8]$

$$
\left[\begin{array}{cc}
\mathbf{M} & \mathbf{M}_{\mathrm{g}} \\
\mathbf{M}_{\mathrm{g}}^{\mathrm{T}} & \mathbf{M}_{\mathrm{gg}}
\end{array}\right]\left[\begin{array}{c}
\ddot{\mathbf{U}}^{\mathrm{t}} \\
\ddot{\mathbf{U}}_{\mathrm{g}}
\end{array}\right]+\left[\begin{array}{cc}
\mathbf{C} & \mathbf{C}_{\mathrm{g}} \\
\mathbf{C}_{\mathrm{g}}^{\mathrm{T}} & \mathbf{C}_{\mathrm{gg}}
\end{array}\right]\left[\begin{array}{c}
\dot{\mathbf{U}}^{\mathrm{t}} \\
\dot{\mathbf{U}}_{\mathrm{g}}
\end{array}\right]+\left[\begin{array}{cc}
\mathbf{K} & \mathbf{K}_{\mathrm{g}} \\
\mathbf{K}_{\mathrm{g}}^{\mathrm{T}} & \mathbf{K}_{\mathrm{gg}}
\end{array}\right]\left[\begin{array}{c}
\mathbf{U}^{\mathrm{t}} \\
\mathbf{U}_{\mathrm{g}}
\end{array}\right]=\left[\begin{array}{c}
\mathbf{0} \\
\mathbf{P g}
\end{array}\right]+\left[\begin{array}{c}
\Lambda \mathbf{f} \\
\mathbf{0}
\end{array}\right]
$$

where $\mathbf{U}^{t}$ and $\mathbf{U}^{\mathrm{g}}$ are the absolute displacement vector of the superstructure and the displacement vector of the supports, respectively. Matrices $\mathbf{M}, \mathbf{C}$, and $\mathbf{K}$ are the system matrices of the structural model. Matrices $\mathbf{M}_{\mathrm{g}}, \mathbf{C}_{\mathrm{g}}$, and $\mathbf{K}_{\mathrm{g}}$ are the mass, damping and elasticcoupling matrices expressing the forces developed in the active DOFs by the motion of the supports. Matrices $\mathbf{M}_{\mathrm{gg}}, \mathbf{C}_{\mathrm{gg}}$, and $\mathbf{K}_{\mathrm{gg}}$ are the mass, damping and stiffness matrices of the supports, respectively. It is desired to determine the displacement vector $\mathbf{U}^{\mathrm{t}}$ in the superstructure DOFs and the support forces $\mathbf{P}_{\mathrm{g}}$. Observe that control forces $\mathbf{f}$ are applied only to the superstructure DOFs.

The total displacement $\mathbf{U}^{\mathrm{t}}$ is expressed as its displacement $\mathbf{U}^{\mathrm{s}}$ due to static application of the ground motion, plus the dynamic displacement $\mathbf{U}$ relative to the quasi-static displacement. Therefore, the relationship between these displacement components is expressed by

$$
\left[\begin{array}{c}
\mathbf{U}^{\mathrm{t}} \\
\mathbf{U}_{\mathrm{g}}
\end{array}\right]=\left[\begin{array}{c}
\mathbf{U}^{\mathrm{s}} \\
\mathbf{U}_{\mathrm{g}}
\end{array}\right]+\left[\begin{array}{l}
\mathbf{U} \\
\mathbf{0}
\end{array}\right]
$$

The two are related through

$$
\left[\begin{array}{cc}
\mathbf{K} & \mathbf{K}_{\mathrm{g}} \\
\mathbf{K}_{\mathrm{g}}^{\mathrm{T}} & \mathbf{K}_{\mathrm{gg}}
\end{array}\right]\left[\begin{array}{c}
\mathbf{U}^{\mathrm{s}} \\
\mathbf{U}_{\mathrm{g}}
\end{array}\right]=\left[\begin{array}{c}
\mathbf{0} \\
\mathbf{P}_{\mathrm{g}}^{\mathrm{s}}
\end{array}\right]
$$

where $\mathbf{P}_{\mathrm{g}}^{\mathrm{s}}$ are the support forces necessary to statically impose displacements $\mathbf{U}_{\mathrm{g}}$ that vary with time; obviously, $\mathbf{U}_{\mathrm{s}}$ varies with time and is therefore known as the vector of quasistatic displacements. Observe that $\mathbf{P}_{\mathrm{g}}^{\mathrm{s}}=0$ if the structure is statically determinate, or if the support system undergoes rigid-body motion; for the latter condition, an obvious example is identical horizontal motion of all supports. The remainder $\mathbf{U}$ of the structural displacements is known as the dynamic displacement vector because the quasi-static displacements cannot be evaluated by rigid-body kinematics.

With the total structural displacements split into quasi-static and dynamic displacements, we return to the first of the two partitioned equations

$$
\mathbf{M} \ddot{\mathbf{U}}^{\mathrm{t}}+\mathbf{M}_{\mathrm{g}} \ddot{\mathbf{U}}_{\mathrm{g}}+\mathbf{C} \dot{\mathbf{U}}^{\mathrm{t}}+\mathbf{C}_{\mathrm{g}} \dot{\mathbf{U}}_{\mathrm{g}}+\mathbf{K} \mathbf{U}^{\mathrm{t}}+\mathbf{K}_{\mathrm{g}} \mathbf{U}_{\mathrm{g}}=\Lambda \mathbf{f}
$$

Substituting Equation (3) and transferring all terms involving $\mathbf{U}_{\mathrm{g}}$ and $\mathbf{U}^{\mathrm{s}}$ to the right-hand side leads to

$$
\mathbf{M U ̈}+\mathbf{C} \dot{\mathbf{U}}+\mathbf{K U}=\Lambda \mathbf{f}-\left(\mathbf{M} \ddot{\mathbf{U}}^{\mathrm{s}}+\mathbf{M}_{\mathrm{g}} \ddot{\mathbf{U}}_{\mathrm{g}}\right)-\left(\mathbf{C} \dot{\mathbf{U}}^{\mathrm{s}}+\mathbf{C}_{\mathrm{g}} \dot{\mathbf{U}}_{\mathrm{g}}\right)-\left(\mathbf{K} \mathbf{U}^{\mathrm{s}}+\mathbf{K}_{\mathrm{g}} \mathbf{U}_{\mathrm{g}}\right)
$$


where the term on the right-hand side is called the vector of effective earthquake forces. The third term of the right-hand side in Equation (6) drops out because Equation (4) gives

$$
\mathbf{K} \mathbf{U}^{\mathrm{s}}+\mathbf{K}_{\mathrm{g}} \mathbf{U}_{\mathrm{g}}=\mathbf{0}
$$

in which the displacement $\mathbf{U}^{\mathrm{s}}$ by definition is the pseudo-static vector. Solving for these displacements leads to

$$
\mathbf{U}^{\mathrm{s}}=-\mathbf{K}^{-1} \mathbf{K}_{\mathrm{g}} \mathbf{U}_{\mathrm{g}}
$$

from which it is apparent that the pseudo-static influence vector is given by

$$
\mathbf{R}_{\mathrm{s}}=-\mathbf{K}^{-1} \mathbf{K}_{\mathrm{g}}
$$

The influence vector describes the influence of support displacements on the structural displacements. Finally, substituting Equations (8) and (9) into Equation (6) gives

$$
\mathbf{M U ̈}+\mathbf{C} \dot{\mathbf{U}}+\mathbf{K} \mathbf{U}=\Lambda \mathbf{f}-\left(\mathbf{M R}_{\mathrm{s}}+\mathbf{M}_{\mathrm{g}}\right) \ddot{\mathbf{U}}_{\mathrm{g}}-\left(\mathbf{C} \mathbf{R}_{\mathrm{s}}+\mathbf{C}_{\mathrm{g}}\right) \dot{\mathbf{U}}_{\mathrm{g}}
$$

If the ground accelerations and velocities are prescribed at each support, this completes the formulation of the governing equation.

For many practical applications, further simplification of the effective force vector is possible. The damping term is zero if the damping matrices are proportional to the stiffness matrices because of Equation (7); this stiffness-proportional damping may be unrealistic, however. While the damping term is not zero for arbitrary forms of damping, it is usually small relative to the inertia term, and may therefore be dropped. Nevertheless, the damping term is included in the governing equation in this benchmark problem.

The element mass and tangent stiffness matrices generated in ABAQUS are summed at each node to assemble the global stiffness and mass matrices within MATLAB. The equations are partitioned into active and constrained DOFs, and constraints were applied by condensing out rigid links (applying kinematic constraints). The resulting model has 909 DOF for the superstructure plus 45 DOF for the supports.

\subsection{Model reduction}

The model resulting from the finite element formulation has a large number of degrees of freedom and high-frequency dynamics. Thus, some assumptions are made regarding the behavior of the bridge to make the model more manageable for dynamic simulation while retaining the fundamental behavior of the bridge. The active DOF retained in the model include: (i) the nodes at the top of each tower; (ii) the lowest nodes at which cables are connected on each tower; (iii) nodes at the joints of the towers; (iv) nodes or DOFs of elements whose shear and overturning moments are among the design criteria; (v) approximately every third node of the bridge deck; and (vi) rotational DOFs about the longitudinal and vertical axis of all spinal deck nodes. These locations are indicated in the finite element model in Figure 4. Note that the support DOF are not eliminated because they are required for determination of the response of the structure to multiple support excitation.

Static condensation is performed by first partitioning the mass and stiffness matrices corresponding to the structure DOF into active and dependent DOF as in

$$
\mathbf{M}=\left[\begin{array}{ll}
\mathbf{M}_{\mathrm{aa}} & \mathbf{M}_{\mathrm{ad}} \\
\mathbf{M}_{\mathrm{da}} & \mathbf{M}_{\mathrm{dd}}
\end{array}\right] \quad \mathbf{K}=\left[\begin{array}{ll}
\mathbf{K}_{\mathrm{aa}} & \mathbf{K}_{\mathrm{ad}} \\
\mathbf{K}_{\mathrm{da}} & \mathbf{K}_{\mathrm{dd}}
\end{array}\right]
$$


Assuming that no loads are applied to the dependent DOFs, the system equation for static equilibrium is written as

$$
\left[\begin{array}{ll}
\mathbf{K}_{\mathrm{aa}} & \mathbf{K}_{\mathrm{ad}} \\
\mathbf{K}_{\mathrm{da}} & \mathbf{K}_{\mathrm{dd}}
\end{array}\right]\left[\begin{array}{c}
\hat{\mathbf{U}} \\
\overline{\mathbf{U}}
\end{array}\right]=\left[\begin{array}{c}
\mathbf{P}_{\mathrm{a}} \\
\mathbf{0}
\end{array}\right]
$$

where $\hat{\mathbf{U}}$ is the active, and $\overline{\mathbf{U}}$ is the dependent displacement vector. Using the second row of Equation (12), the transformation matrix is obtained as

$$
\mathbf{T}_{\mathrm{R}}=\left[\begin{array}{c}
\mathbf{I} \\
-\mathbf{K}_{\mathrm{dd}}^{-1} \mathbf{K}_{\mathrm{da}}
\end{array}\right]
$$

where $\mathbf{T}_{\mathrm{R}}$ is the static transformation matrix, and $\mathbf{I}$ is an identity matrix of appropriate size, such that

$$
\left[\begin{array}{c}
\hat{\mathbf{U}} \\
\overline{\mathbf{U}}
\end{array}\right]=\mathbf{T}_{\mathrm{R}} \hat{\mathbf{U}}
$$

The transformed mass and stiffness matrices are then as follows

$$
\hat{\mathbf{M}}=\mathbf{T}_{\mathrm{R}}^{\mathrm{T}} \mathbf{M} \mathbf{T}_{\mathrm{R}} \quad \text { and } \quad \hat{\mathbf{K}}=\mathbf{T}_{\mathrm{R}}^{\mathrm{T}} \mathbf{K} \mathbf{T}_{\mathrm{R}}
$$

The corresponding coefficient matrices for the ground excitation and the control forces are given by

$$
\hat{\Gamma}=\mathbf{T}_{\mathrm{R}}^{\mathrm{T}} \mathbf{M} \Gamma \quad \text { and } \quad \hat{\Lambda}=\mathbf{T}_{\mathrm{R}}^{\mathrm{T}} \Lambda
$$

Note that prior to making this transformation, $\boldsymbol{\Gamma}$ and $\boldsymbol{\Lambda}$ must be reordered into active and dependent DOF. Application of this reduction scheme to the full model of the bridge resulted in a 419-DOF reduced order model. The first 100 natural frequencies of the reduced model (up to $3.5 \mathrm{~Hz}$ ) were compared and are in good agreement with those of the 909-DOF structure.

The damping in the system is defined based on the assumption of modal damping. The damping matrix was developed by assigning $3 \%$ of critical damping to each mode. This value was selected to be consistent with assumptions made during the design of the bridge. The reduced system was used to construct the damping matrix, using

$$
\hat{\mathbf{C}}=\hat{\mathbf{M}} \boldsymbol{\Phi}\left[\begin{array}{ccc}
2 \zeta_{1} \omega_{1} & 0 & 0 \\
0 & \ldots & 0 \\
0 & 0 & 2 \zeta_{n} \omega_{n}
\end{array}\right] \Phi^{-1}
$$

where $\Phi$ is the modal matrix, and $\omega_{i}$ and $\zeta_{i}$ are the natural frequency $[\mathrm{rad} / \mathrm{s}]$ and modal damping ratio of the $i$ th mode, respectively.

After model reduction the resulting equation of motion for the damped structural system from Equation (10) is

$$
\hat{\mathbf{M}} \ddot{\mathbf{U}}+\hat{\mathbf{C}} \dot{\mathbf{U}}+\hat{\mathbf{K}} \hat{\mathbf{U}}=\Lambda \mathbf{f}-\left(\hat{\mathbf{M}} \hat{\mathbf{R}}+\mathbf{M}_{\mathrm{g}}\right) \ddot{\mathbf{U}}_{\mathrm{g}}-\left(\hat{\mathbf{C}} \hat{\mathbf{R}}_{\mathrm{s}}+\mathbf{C}_{\mathrm{g}}\right) \dot{\mathbf{U}}_{\mathrm{g}}
$$

where $\hat{\mathbf{R}}_{\mathrm{s}}=-\hat{\mathbf{K}}^{-1} \mathbf{K}_{\mathrm{g}}$ and $\hat{\mathbf{U}}$ is the displacement vector of active structural DOFs. This model is designated the evaluation model. It is considered to portray the actual dynamics of the bridge, and will be used to evaluate various control systems. Note that this model always includes the effects of the shock transmission devices, which constraint longitudinal motion. The evaluation 


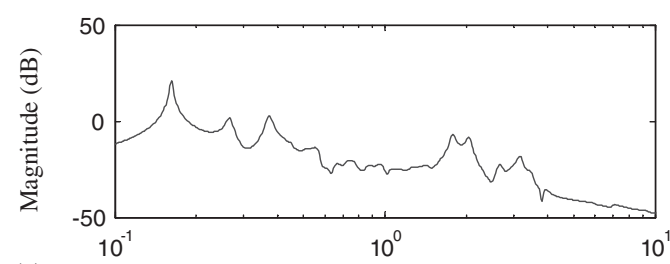

(a)
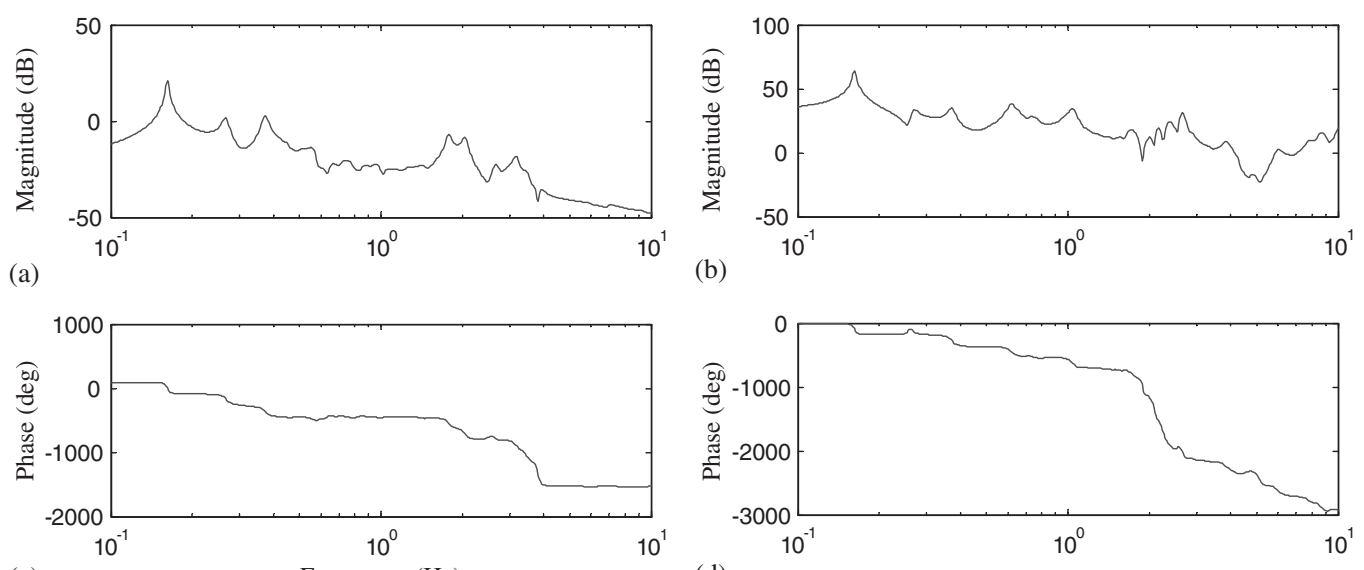

(b)

(c)

Frequency $(\mathrm{Hz})$

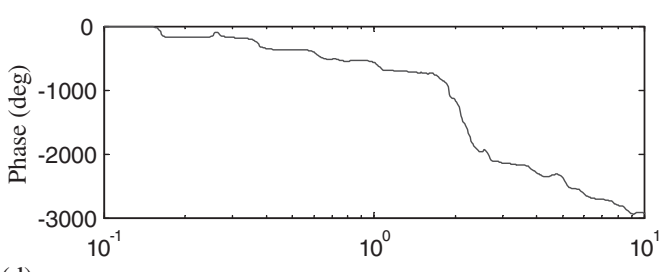

(d)

Frequency $(\mathrm{Hz})$

Figure 5. Representative transfer functions of the bridge model: (a) longitudinal ground acceleration to acceleration $(X)$ at the top of pier 2; (b) ground acceleration to the shear force at the deck level at pier 2.

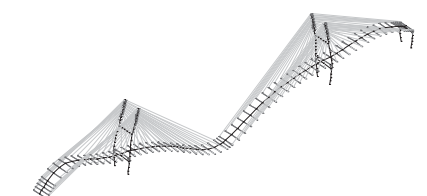

First Mode Shape (Vertical, .2899Hz)

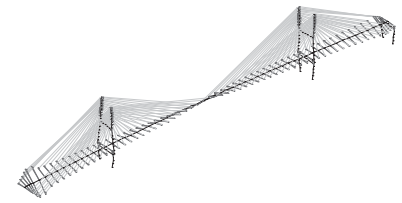

Third Mode Shape (Torsion, .4683 Hz)

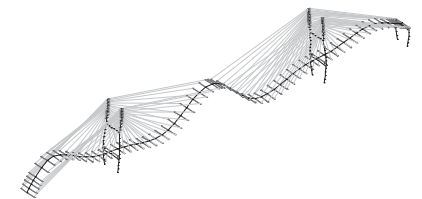

Fifth Mode Shape (Vertical, .5812 Hz)
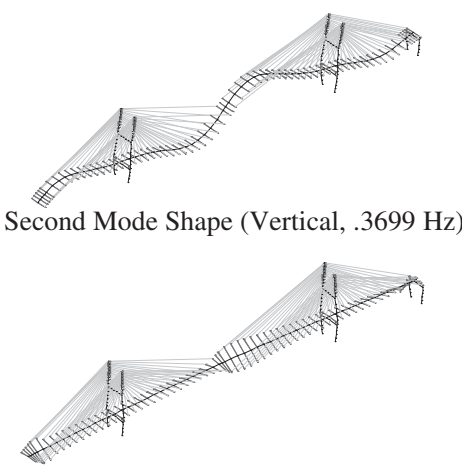

Fourth Mode Shape (Torsion, . $5158 \mathrm{~Hz}$ )

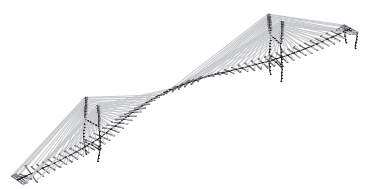

Sixth Mode Shape (Lateral+Torsional, $.6490 \mathrm{~Hz}$ )

Figure 6. Representative mode shapes of the bridge evaluation model.

model and earthquake inputs are fixed for this benchmark problem. Two representative transfer functions are shown in Figure 5 and the first few mode shapes are shown in Figure 6.

\subsection{Alternate model for assessment of robustness}

An alternate model is developed to evaluate the robust performance of the proposed control designs. To develop the alternate model, the effects of snow loads on the model are considered. 
UBC codes [16] indicate that the ground snow load in the Cape Girardeau region is $73.3 \mathrm{~kg} / \mathrm{m}^{2}$ (15 psf) for 50 -year mean recurrence interval. In addition to the snow load, $24.4 \mathrm{~kg} / \mathrm{m}^{2}$ ( $5 \mathrm{psf}$ ) should be added for zones with frequent rain and snow. Snow with a mass per length of $97.7 \mathrm{~kg} / \mathrm{m}^{2}$ (20 psf) are added to the deck, and its effect perturbs the mass matrix of the model. This amount increases the mass of the bridge by approximately $3.5 \%$. The nominal evaluation model has the following first ten undamped natural frequencies: $0.2899,0.3699,0.4683,0.5158$, $0.5812,0.6490,0.6687,0.6970,0.7102$, and $0.7203 \mathrm{~Hz}$. The second evaluation model, considering snow loads, has the following first ten undamped natural frequencies: $0.2790,0.3559,0.4489$, $0.4969,0.5589,0.6230,0.6406,0.6809,0.6816,0.6971 \mathrm{~Hz}$. The maximum variation in these frequencies is $4.38 \%$. The second model is to be used to investigate the robustness of the control system with respect to the uncertainties in mass.

\section{ANALYSIS TOOL}

The linear model of the bridge system is simulated by a version of the analysis tool developed by Ohtori and Spencer [17] for linear systems. This tool allows the user to implement the compiled $\mathrm{C}$ code from within the MATLAB environment through a SIMULINK block to simulate the responses of a seismically excited structural system. Although the full version of the program may be used for nonlinear analysis, the version included in this benchmark problem is applicable only to linear systems.

To use the code, one must define the mass, stiffness, and damping matrices for the evaluation structure ( $\hat{\mathbf{M}}, \hat{\mathbf{C}}$, and $\hat{\mathbf{K}}$ in Equation (18)), as well as the matrices defining the inputs and outputs of the structural system. The input and output matrices are found using the state space form of Equation (18) given by

$$
\dot{\mathbf{x}}=\mathbf{A}_{\mathrm{e}} \mathbf{x}+\mathbf{B}_{\mathrm{e}}\left[\begin{array}{c}
\ddot{\mathbf{U}}_{\mathrm{g}} \\
\dot{\mathbf{U}}_{\mathrm{g}} \\
\mathbf{f}
\end{array}\right] \mathbf{y}=\mathbf{C}_{\mathrm{e}} \mathbf{x}+\mathbf{D}_{\mathrm{e}}\left[\begin{array}{c}
\ddot{\mathbf{U}}_{\mathrm{g}} \\
\dot{\mathbf{U}}_{\mathbf{g}} \\
\mathbf{f}
\end{array}\right]
$$

where $\dot{\mathbf{x}}=\left[\hat{\mathbf{U}}^{T} \dot{\hat{\mathbf{U}}}^{T}\right]^{T}$ is the state vector, $\mathbf{A}_{\mathrm{e}}$ is the state matrix, and $\mathbf{B}_{\mathrm{e}}, \mathbf{C}_{\mathrm{e}}$, and $\mathbf{D}_{\mathrm{e}}$ are determined by the inputs and outputs selected by the designer or researcher.

These matrices must be available in the MATLAB workspace to perform the simulation. Note that the analysis tool does not require use of the $\mathbf{A}_{\mathrm{e}}$ matrix, although it is available to the researcher or designer for possible use in developing a control-oriented model of the bridge.

\section{CONTROL DESIGN PROBLEM STATEMENT}

As stated previously the researcher or designer must define the sensors, devices, and algorithms to be used in his or her control strategy. These must be defined in specific forms to interface properly with the benchmark bridge model. The sensors and control devices interface with the bridge model through measurement and connection outputs, designated $\mathbf{y}_{\mathrm{m}}$ and $\mathbf{y}_{\mathrm{c}}$, respectively (Figure 7). Additionally participants define the components of the evaluation output vector, designated $\mathbf{y}_{\mathrm{e}}$. The components of $\mathbf{y}_{\mathrm{m}}, \mathbf{y}_{\mathrm{c}}$, and $\mathbf{y}_{\mathrm{e}}$ are specified within an input/output file provided with the benchmark problem statement. A MATLAB graphical user interface is 


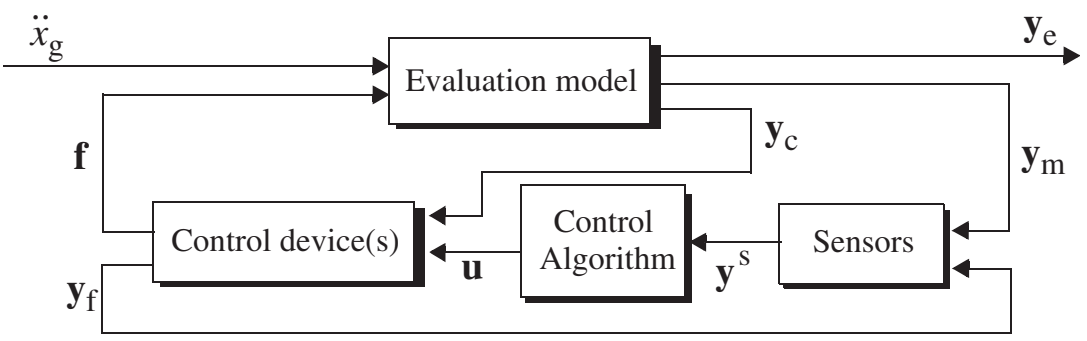

Figure 7. Block diagram of the control system.

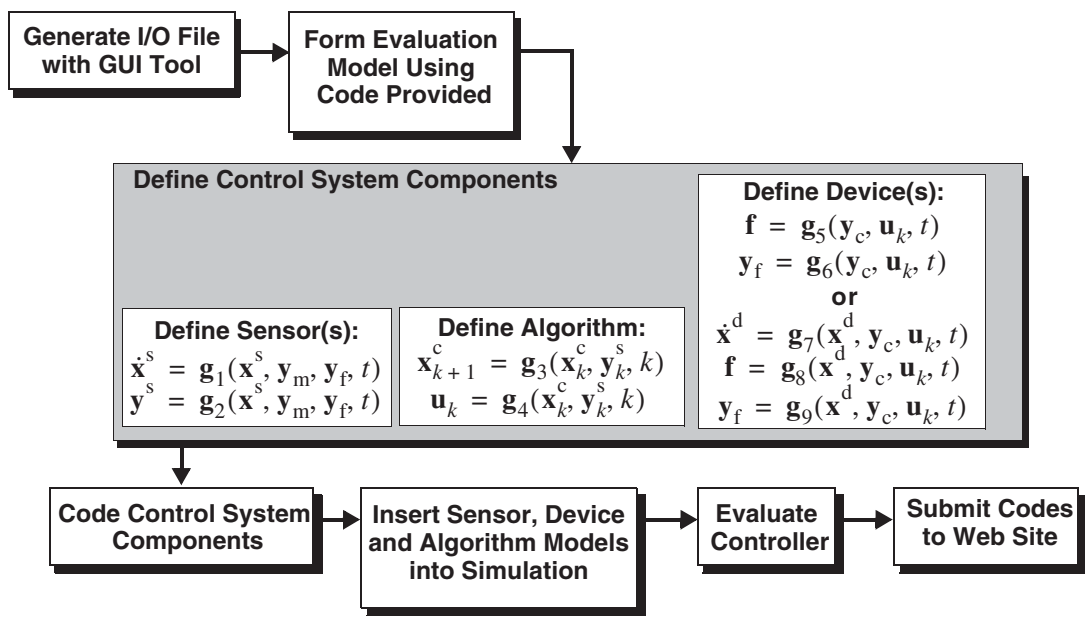

Figure 8. Flowchart of benchmark solution procedure.

provided to simplify this procedure. However, this information can be inserted directly into the input/output file in terms of the node numbers if preferred (Figure 8).

\subsection{Control system components}

The sensors must be defined to measure the outputs of the evaluation model. Researchers and designers must develop models for the sensors which must take the following form

$$
\begin{aligned}
\dot{\mathbf{x}}^{\mathrm{s}} & =\mathbf{g}_{1}\left(\mathbf{x}^{\mathrm{s}}, \mathbf{y}_{\mathrm{m}}, \mathbf{y}_{\mathrm{f}}, t\right) \\
\mathbf{y}^{\mathrm{s}} & =\mathbf{g}_{2}\left(\mathbf{x}^{\mathrm{s}}, \mathbf{y}_{\mathrm{m}}, \mathbf{y}_{\mathrm{f}}, t\right)
\end{aligned}
$$

where $\mathbf{x}^{\mathrm{s}}$ is the continuous-time state vector of the sensor(s) and $\mathbf{y}^{\mathrm{s}}$ is the continuous-time output of the sensor(s) (measured in Volts), $\mathbf{y}_{\mathrm{f}}$ is the continuous-time output vector from the control device model (see Equations (26-28)), which may include forces produced by individual control devices, device stroke, device acceleration, and is used for evaluation of the control strategy and is available for feedback in the control algorithm.

Passive, active, and semi-active control devices (or combinations thereof) may be used in designing control systems. For active or semi-active control systems, the associated discrete-time 
control algorithm must take the form

$$
\begin{gathered}
\mathbf{x}_{k+1}^{\mathrm{c}}=\mathbf{g}_{3}\left(\mathbf{x}_{k}^{\mathrm{c}}, \mathbf{y}_{k}^{\mathrm{s}}, k\right) \\
\mathbf{u}_{k}=\mathbf{g}_{4}\left(\mathbf{x}_{k}^{\mathrm{c}}, \mathbf{y}_{k}^{\mathrm{s}}, k\right)
\end{gathered}
$$

where $\mathbf{x}_{k}^{\mathrm{c}}$ is the discrete-time state vector of the control algorithm at each sampling time $t=k T, \boldsymbol{y}_{k}^{\mathrm{s}}$, is the discrete-time input to the control algorithm from the sensors (which should be discretized in time and quantized to represent an $\mathrm{A} / \mathrm{D}$ converter), and $\mathbf{u}_{k}$ is the discrete-time control command from the control algorithm.

Dynamic models of the control devices selected by the researcher/designer are not required for this benchmark study. Ideal control devices may be assumed. Note that the program allows designers and researchers to place control devices at constrained nodes although errors will result in the simulated responses. To interface with the benchmark bridge model the control device model(s) must take the form

$$
\begin{gathered}
\mathbf{f}=\mathbf{g}_{5}\left(\mathbf{y}_{\mathrm{c}}, \mathbf{u}_{k}, t\right) \\
\mathbf{y}_{\mathrm{f}}=\mathbf{g}_{6}\left(\mathbf{y}_{\mathrm{c}}, \mathbf{u}_{k}, t\right)
\end{gathered}
$$

where $\mathbf{y}_{\mathrm{c}}$ contains the continuous-time responses from the evaluation model that influence the control forces, and is the continuous-time force output of the control device(s) applied to the structure (in $\mathrm{kN}$ ). Researchers or designers who choose to employ dynamic models of their control devices should use the form

$$
\begin{gathered}
\dot{\mathbf{x}}^{\mathrm{d}}=\mathbf{g}_{7}\left(\mathbf{x}^{\mathrm{d}}, \mathbf{y}_{\mathrm{c}}, \mathbf{u}_{k}, t\right) \\
\mathbf{f}=\mathbf{g}_{8}\left(\mathbf{x}^{\mathrm{d}}, \mathbf{y}_{\mathrm{c}}, \mathbf{u}_{k}, t\right) \\
\mathbf{y}_{\mathrm{f}}=\mathbf{g}_{9}\left(\mathbf{x}^{\mathrm{d}}, \mathbf{y}_{\mathrm{c}}, \mathbf{u}_{k}, t\right)
\end{gathered}
$$

where $\mathbf{x}^{\mathrm{d}}$ is the continuous-time state vector of the control device.

\subsection{GUI tool}

A MATLAB-based graphical user interface (GUI) tool has been developed to aid the researcher or designer in generating the input/output information for the evaluation model. The graphical user interface allows the user to select the node numbers defining the evaluation outputs $\mathbf{y}_{\mathrm{e}}$, the connection outputs $\mathbf{y}_{\mathrm{c}}$, and the measured outputs $\mathbf{y}_{\mathrm{m}}$, for use in each control strategy. The location of the control devices may also be specified within the GUI. Once the control system setup is specified, the user may choose to generate the evaluation model from within the GUI or from the MATLAB command window directly.

\subsection{Evaluation criteria}

For cable-stayed bridges subjected to earthquake loading, critical responses are related to the structural integrity of the bridge rather than to serviceability issues. Thus, in evaluating the performance of each control algorithm, the shear forces and moments in the towers at key locations (see Figure 3) must be considered. Additionally, the tension in the cables should never approach zero, and should remain close to the nominal pretension. 
A set of 18 criteria have been developed to evaluate the capabilities of each control strategy. Because the earthquake is assumed to have two horizontal components at a specified incidence angle, several of these criteria are evaluated in both the $X$ (longitudinal) and $Z$ (transverse) directions. The first six evaluation criteria consider the ability of the controller to reduce peak responses, the second five criteria consider normed responses over the entire time record, and the last seven criteria consider the requirements of the control system itself.

For each control design, the evaluation criteria should be evaluated for each of three earthquake records provided in the benchmark problem: (i) El Centro. Recorded at the Imperial Valley Irrigation District substation in El Centro, California, during the Imperial Valley, California earthquake of 18 May 1940; (ii) Mexico City. Recorded at the Galeta de Campos station with site geology of meta-andesite breccia on 19 September 1985; (iii) Gebze, Turkey. The Kocaeli earthquake recorded at the Gebze Tubitak Marmara Arastirma Merkezi on 17 August 1999. The Mexico City earthquake is selected because geological studies have indicated that the Cape Girardeau region is similar to Mexico City. The El Centro and Gebze earthquakes allow for the researcher or designer to test his or her control strategies on earthquakes with different characteristics. These three earthquakes are each at or below the design peak ground acceleration level for the bridge of $0.36 \mathrm{~g}$.

To consider multi-support excitations, the prescribed ground motion is assumed to be identical at each support, although it is not simultaneous. Bent 1 is assumed to experience a specified ground motion, and the motion at the other three supports is delayed, based on the distance between adjacent supports and the speed of the L-wave of a typical earthquake $(3 \mathrm{~km} / \mathrm{s})$. For each control design, the evaluation criteria should be evaluated for each specified excitation case: case $\mathrm{A}$, an incidence angle of $15^{\circ}$ with arrival times of $\left[\begin{array}{llll}0 & 0.05 & 0.16 & 0.20\end{array}\right] \mathrm{s}$, and case $\mathrm{B}$, an incidence angle of $45^{\circ}$ with arrival times of [ 00.030 .120 .15 ] s. The incidence angle is defined between the longitudinal direction of the bridge and the $\mathrm{N}-\mathrm{S}$ wave of the earthquake. Researchers and designers may evaluate their control designs for additional incidence angles by modifying the input file.

The first two evaluation criteria are dimensionless measures of the shear force at key locations in the towers. The elevation of these key locations correspond to the tower base and the deck level (see Figure 3). The latter criterion was selected because this elevation corresponds to a drastic reduction in the cross-sectional area of the towers. This first two evaluation criteria are given by

$$
\begin{gathered}
J_{1}=\max _{\substack{\text { El Centro } \\
\text { Mexico City } \\
\text { Gebze }}}\left\{\frac{\max _{i, t}\left|F_{\mathrm{b} i}(t)\right|}{F_{0 \mathrm{~b}}^{\max }}\right\} \\
J_{2}=\max _{\substack{\text { El Centro } \\
\text { Mexico City } \\
\text { Gebze }}}\left\{\frac{\max _{i, t}\left|F_{\mathrm{d} i}(t)\right|}{F_{0 \mathrm{~d}}^{\max }}\right\}
\end{gathered}
$$

where $F_{\mathrm{b} i}$ is the base shear at the $i$ th tower, $F_{0 \mathrm{~b}}^{\max }=\max _{i, t}\left|F_{0 \mathrm{~b} i}(t)\right|$ is the maximum uncontrolled base shear (of the values at the two towers), $F_{\mathrm{d} i}(t)$ is the shear at the deck level in the $i$ th tower (see Figure 3), $F_{0 \mathrm{~d}}^{\max }=\max _{i, t}\left|F_{0 \mathrm{~d} i}(t)\right|$ is the maximum uncontrolled shear at the deck level, and $|\cdot|$ indicates absolute value. The values of $F_{0 \mathrm{~b}}^{\max }, F_{0 \mathrm{~d}}^{\max }$, and all other values used to normalize the evaluation criteria, are provided in Tables VI-VII of the Appendix. 
The second set of evaluation criterion are dimensionless measures of the moments in the towers at the same key locations, given by

$$
\begin{gathered}
J_{3}=\max _{\substack{\text { El Centro } \\
\text { Mexico City } \\
\text { Gebze }}}\left\{\frac{\max _{i, t}\left|M_{\mathrm{bi}}(t)\right|}{M_{0 \mathrm{~b}}^{\max }}\right\} \\
J_{4}=\max _{\substack{\text { El Centro } \\
\text { Mexico City } \\
\text { Gebze }}}\left\{\frac{\max _{i, t}\left|M_{\mathrm{d} i}(t)\right|}{M_{0 \mathrm{~d}}^{\max }}\right\}
\end{gathered}
$$

where $M_{\mathrm{b} i}(t)$ is the moment at the base of the $i$ th tower, $M_{0 \mathrm{~b}}^{\max }=\max _{i, t}\left|M_{0 \mathrm{~b} i}(t)\right|$ is the maximum uncontrolled moment at the base of the two towers, $M_{\mathrm{d} i}(t)$ is the moment at the deck level in the ith tower, and $M_{0 \mathrm{~d}}^{\max }=\max _{i, t}\left|M_{0 \mathrm{~d} i}(t)\right|$ is the maximum uncontrolled moment at the deck level in the two towers.

The fifth evaluation criterion is a dimensionless measure of the deviation of the tension in the stay cables from the nominal pretension, given by

$$
J_{5}=\max _{\substack{\text { El Centro } \\ \text { Mexico City } \\ \text { Gebze }}}\left\{\max _{i, t} \frac{\left|T_{\mathrm{a} i}(t)-T_{0 i}\right| / T_{0 i}}{T_{0 \mathrm{c}}^{\max }}\right\}
$$

where $T_{0 i}$ is the nominal pretension in the $i$ th cable, $T_{\mathrm{a} i}(t)$ is the actual tension in the cable as a function of time, and $T_{0 \mathrm{c}}^{\max }=\max _{i, t}\left(\left|T_{\mathrm{a} 0 i}(t)-T_{0 i}\right| / T_{0 i}\right)$ is the normalized actual cable tension of the uncontrolled system. This criterion is selected to reduce the likelihood of failure or unseating of the cables.

The sixth evaluation criterion is a measure of the peak deck displacement at piers 1 and 4 .

$$
J_{6}=\max _{\substack{\text { El Centro } \\ \text { Mexico City } \\ \text { Gebze }}}\left\{\max _{i, t}\left|\frac{x_{\mathrm{bi}}(t)}{x_{0 \mathrm{~b}}}\right|\right\}
$$

where $x_{\mathrm{b} i}(t)$ is the displacement of the bridge deck at the $i$ th location and $x_{0 \mathrm{~b}}$ is the maximum of the uncontrolled deck response at these locations. This criterion is included to consider the possibility of impact on the deck at these locations.

The seventh and eighth evaluation criteria are dimensionless measures of the normed values of the base shear and shear at the deck level in each of the towers, respectively, given by

$$
\begin{gathered}
J_{7}=\max _{\substack{\text { El Centro } \\
\text { Mexico City } \\
\text { Gebze }}}\left\{\frac{\max _{i}\left\|F_{\mathrm{b} i}(t)\right\|}{\left\|F_{0 \mathrm{~b}}(t)\right\|}\right\} \\
J_{8}=\max _{\substack{\text { El Centro } \\
\text { Mexico City } \\
\text { Gebze }}}\left\{\frac{\max _{i}\left\|F_{\mathrm{d} i}(t)\right\|}{\left\|F_{0 \mathrm{~d}}(t)\right\|}\right\}
\end{gathered}
$$

where $\left\|F_{0 \mathrm{~b}}(t)\right\|$ is the maximum of the normed value of the uncontrolled base shear of the two towers, and $\left\|F_{0 \mathrm{~d}}(t)\right\|$ is the maximum of the normed value of the uncontrolled shear at the deck 
level of the tower. The normed value of the response, denoted by $\|\cdot\|$, is defined as

$$
\|\cdot\| \equiv \sqrt{\frac{1}{t_{f}} \int_{0}^{t_{f}}(\cdot)^{2} \mathrm{~d} t}
$$

where $t_{f}$ is defined as the time required for the response to attenuate.

The ninth and tenth evaluation criteria are dimensionless measures of the normed values of the overturning moment and moment at the deck level in each of the towers, respectively, given by

$$
\begin{gathered}
J_{9}=\max _{\substack{\text { El Centro } \\
\text { Mexico City } \\
\text { Gebze }}}\left\{\frac{\max _{i}\left\|M_{\mathrm{b} i}(t)\right\|}{\left\|M_{0 \mathrm{~b}}(t)\right\|}\right\} \\
J_{10}=\max _{\substack{\text { El Centro } \\
\text { Mexico City } \\
\text { Gebze }}}\left\{\frac{\max _{i}\left\|M_{\mathrm{d} i}(t)\right\|}{\left\|M_{0 \mathrm{~d}}(t)\right\|}\right\}
\end{gathered}
$$

where $\left\|M_{0 \mathrm{~b}}(t)\right\|$ is the maximum of the normed value of the uncontrolled moment at the base of the two towers, and $\left\|M_{0 \mathrm{~d}}(t)\right\|$ is the maximum of the normed value of the uncontrolled moment at the deck level of the two towers.

The eleventh evaluation criterion is a dimensionless measure of the normed value of the deviation of the tension in the stay cables from the nominal pretension, given by

$$
J_{11}=\max _{\substack{\text { El Centro } \\ \text { Mexico City } \\ \text { Gebze }}}\left\{\max _{i, t} \frac{\left\|T_{\mathrm{a} i}(t)-T_{0 i}\right\| / T_{0 i}}{\left\|T_{0 \mathrm{c}}\right\|}\right\}
$$

where $T_{0 i}$ is the existing pretension in the $i$ th cable, $T_{\mathrm{a} i}(t)$ is the actual tension in the $i$ th cable as a function of time, and $\left\|T_{0 \mathrm{c}}\right\|=\max _{i, t}\left(\left\|T_{\mathrm{a} 0 i}(t)-T_{0 i}\right\| / T_{0 i}\right)$ is the maximum of the normed value of the actual cable tension for the uncontrolled system.

The twelfth evaluation criterion deals with the maximum force generated by the control device(s) and is described as

$$
J_{12}=\max _{\substack{\text { El Centro } \\ \text { Mexico City } \\ \text { Gebze }}}\left\{\max _{i, t}\left(\frac{f_{i}(t)}{W}\right)\right\}
$$

where $f_{i}(t)$ is the force generated by the $i$ th control device over the time history of each earthquake, and $W=510000 \mathrm{kN}(114,640 \mathrm{kips})$ is the seismic weight of the bridge, based on the mass of the superstructure (not including the foundation).

The thirteenth criterion is based on the maximum stroke of the control device(s). This performance measure is given as

$$
J_{13}=\max _{\substack{\text { El Centro } \\ \text { Mexico City } \\ \text { Gebze }}}\left\{\max _{i, t}\left(\frac{\left|y_{i}^{\mathrm{d}}(t)\right|}{x_{0}^{\max }}\right)\right\}
$$

where $y_{i}^{\mathrm{d}}(t)$ is the stroke of the $i$ th control device over the time history of each earthquake, and $x_{0}^{\max }$ is the maximum uncontrolled displacement at the top of the towers relative to the ground. 
When devices are used that do not have an associated stroke (e.g. tuned liquid dampers), the researcher or designer should assume this evaluation constraint is zero.

The fourteenth evaluation criterion is a dimensionless measure of the maximum instantaneous power required to control the bridge, and is defined as

$$
J_{14}=\max _{\substack{\text { El Centro } \\ \text { Mexico City } \\ \text { Gebze }}}\left\{\frac{\max _{t}\left[\sum_{i} P_{i}(t)\right]}{\dot{x}_{0}^{\max } W}\right\}
$$

where $P_{i}(t)$ is a measure of the instantaneous power required by the $i$ th control device, and $\dot{x}_{0}^{\max }$ is the peak uncontrolled velocity at the top of the towers relative to the ground. Values for $\dot{x}_{0}^{\max }$ are provided in the Appendix (Tables VI, VII) for each of the earthquakes specified. For active control devices, $P_{i}(t) \equiv\left|\dot{y}_{i}^{\mathrm{d}}(t) f_{i}(t)\right|$, where $\dot{y}_{i}^{\mathrm{d}}(t)$ is the velocity of the $i$ th control device. When semi-active devices are employed, $P_{i}(t)$ is the actual power required to operate the device. For passive control devices, this criterion is zero.

The fifteenth evaluation criterion is a dimensionless measure of the total power required to control the bridge, and is defined as

$$
J_{15}=\max _{\substack{\text { El Centro } \\ \text { Mexico City } \\ \text { Gebze }}}\left\{\frac{\sum_{i}\left(\int_{0}^{t_{f}} P_{i}(t) \mathrm{d} t\right)}{x_{0}^{\max } W}\right\}
$$

This criterion is zero when passive device(s) are used.

The sixteenth evaluation criterion is a measure of the total number of control devices required in the control system to control the bridge.

$$
J_{16}=\text { number of control devices }
$$

The seventeenth evaluation criterion is a measure of the total number of sensors required for the proposed control strategy.

$$
J_{17}=\text { number of sensors }
$$

The final evaluation criterion provides a measure of the resources required to implement the control algorithm and is given by

$$
J_{18}=\operatorname{dim}\left(\mathbf{x}_{k}^{\mathrm{c}}\right)
$$

where $\mathbf{x}_{k}^{\mathrm{c}}$ is the discrete-time state vector of the control algorithm given in Equation (22).

All criteria except $J_{5}, J_{6}, J_{7}, J_{16}-J_{18}$ are dependent on direction and should be evaluated for both the $X$ and $Z$ directions.

A summary of the evaluation criteria is provided in Table I. The values of the uncontrolled responses for the three earthquakes required to calculate the evaluation criteria are provided in Tables VI-VII. All criteria should be reported for each proposed controller and for both case A and B. The Mexico City, El Centro, and Gebze earthquakes should all be considered in determining the evaluation criteria. However, designers and researchers are encouraged to include additional criteria in their results if, through these criteria, their results demonstrate an overall desirable quality. An example of such a situation might be a control system that performs well for one type of earthquake, but marginally for other earthquakes, used to evaluate the control strategy. 


\subsection{Control strategy implementation constraints and procedures}

To allow researchers and designers to compare and contrast various control strategies, each of the controllers must be subjected to a uniform set of constraints and procedures. These constraints and procedures are specified below:

1. The measured outputs directly available for use in determining the control action are the absolute accelerations of the bridge at the nodes of the finite element model, and control device outputs which are readily available (e.g. device stroke, force, or absolute acceleration). Although absolute velocity measurements are not available, appropriate filtering of the absolute accelerations may be performed to approximate the velocity responses $[18,19]$. If pseudo-velocity measurements are used, the designer or researcher should specify the filter used in the sensor model (see Equations 20,21).

2. The digitally implemented controller has a sampling time of $T=0.02 \mathrm{~s}$. This sampling time should be set equal to the integration step of the simulation.

3. The $\mathrm{A} / \mathrm{D}$ and $\mathrm{D} / \mathrm{A}$ converters on the digital controller have 16-bit precision and a span of $\pm 10 \mathrm{~V}$.

4. Each of the measured responses contains an rms noise of $0.03 \mathrm{~V}$, which is approximately $0.3 \%$ of the full span of the $\mathrm{A} / \mathrm{D}$ converters. The measurement noises are modeled as Gaussian rectangular pulse processes with a pulse width equal to the integration step.

5. Currently available real-time control implementation hardware is impressive. However, such hardware has limitations and the number of calculations in the control scheme should be kept to a reasonable number. The designer or researcher should justify that the proposed algorithm(s) can be implemented with currently available computing hardware.

6. The control algorithm is required to be stable. The stability robustness for each proposed active control design should be discussed by each researcher or designer.

7. The evaluation criteria of each researcher or designer's controller should be evaluated by the evaluation model, the SIMULINK diagram provided, and each of the earthquake records provided in the benchmark problem. In addition, the values of the evaluation criteria should be provided for the model with snow loads to demonstrate robust performance.

8. Designers and researchers are requested to submit a program that will produce each of the evaluation criterion specified in this problem statement. The resulting controllers will be included on the web page for the second-generation benchmark bridge control problem. Instructions on the formatting of these files are included in the information provided with the benchmark files.

9. Designers and researchers are required to submit the SIMULINK blocks used for controller performance evaluations. For each controller, one sensor block, one control algorithm block, and one control device block should be submitted.

10. Tension in the stay cables should remain within a recommended range of allowable values. A lower bound is necessary to ensure that unseating of a cable does not occur, and an upper bound provides a factor of safety to prevent failure of the cable. The tension in the ith cable may not exceed $0.7 T_{\mathrm{f} i}$ or fall below $0.2 T_{\mathrm{f} i}$, where $T_{\mathrm{f} i}$ is the tension that would cause failure of the ith cable. Values for $T_{\mathrm{f} i}$ are included in the benchmark problem programs. 
11. Because the $\mathrm{D} / \mathrm{A}$ converters have a range of $\pm 10 \mathrm{~V}$, the command signal to each control device has a constraint of $\max _{t}\left|u_{i}^{k}(t)\right| \leqslant 10 \mathrm{~V}$, where $u_{i}^{k}(t)$ is the $i$ th component of the control signal.

12. Each control device employed should be described in terms of the maximum force that can be generated. Researchers and designers must demonstrate that this force constraint is met during each of the earthquakes.

13. Any additional constraints that are unique to each control scheme should also be reported (i.e. maximum stroke of control device, maximum velocity of control device, etc.). Control devices should be selected to allow for expansion of the bridge due to temperature effects.

\section{SAMPLE CONTROL SYSTEM DESIGN}

The following sample control design serves as a guide to the participants in this study, and will lead them through the constraints and design criteria that are set forth in the previous sections. The sample controller is an active control system designed for the linearized cable-stayed bridge model. Accelerometers and displacement transducers are used for feedback to the control algorithm. The sample control system employs a total of 24 hydraulic actuators located between the deck and abutment, and the deck and the towers, and oriented to apply forces longitudinally (global $X$ direction). Therefore, to implement this controller one would replace the shock transmission devices in the bridge with hydraulic actuators. Thus, the modified model (see Section 3) is used for the control design. For simplicity in this sample control design, the control devices act as ideal force actuators, and actuator dynamics and control-structure interaction is neglected. In the following sections we describe the various components of the control system. Models of the sensors and actuators used in the sample design are provided and discussed. A linear quadratic Gaussian design is presented for this active controller. This sample has been prepared to serve as a guide to designers and researchers, and is not intended to be competitive.

\subsection{Sensors}

In the control of civil engineering structures absolute acceleration measurements are readily available. Additionally, measurements of the control devices themselves are typically available. Fourteen accelerometers and four displacement sensors are employed in the sample control system. Six accelerometers are located on top of the tower legs, including four oriented to measure longitudinal $(X)$ acceleration (nodes 240, 248, 353, 361), and two to measure transverse $(Z)$ accelerations (nodes 240, 353). Eight accelerometers are located on the deck, including one at mid-span (node 34 ) oriented to measure longitudinal accelerations, and seven oriented to measure transverse accelerations (nodes $8,11,25,34,43,57,60$ ). The natural frequency of the selected accelerometers are assumed to have a value that is at least an order of magnitude higher than the highest natural frequency we are interested in controlling. Thus the selected accelerometers have a flat response to approximately $3000 \mathrm{rad} / \mathrm{s}$ (i.e. a constant magnitude and phase), and sensor dynamics can be neglected. Two displacement sensors are positioned between the deck and pier 2 , node pairs $(84,313),(151,314)$, and two displacement sensors are located between the deck and pier 3 , node pairs $(118,428),(185,429)$. These sensors are also assumed to have a flat frequency response to $3000 \mathrm{rad} / \mathrm{s}$ or greater. All displacement measurements are obtained in the longitudinal direction to the bridge (global $X$-direction). 
To ensure that the accelerations and displacement measured on the bridge are within the range of the A/D converters, sensors are selected with a sensitivity of $7 \mathrm{~V} / g$ (i.e. $7 \mathrm{~V}=9.81 \mathrm{~m} / \mathrm{s}^{2}$ ) for the accelerometers and a sensitivity of $30 \mathrm{~V} / \mathrm{m}$ (i.e. $10 \mathrm{~V}=0.33 \mathrm{~m}$ ) for the displacement sensors. Thus the sensor system is defined in the form of Equations (20-21) as

$$
\mathbf{y}^{\mathrm{s}}=\mathbf{D}_{\mathrm{s}} \mathbf{y}_{\mathrm{m}}+\mathbf{v}
$$

where $\mathbf{y}^{\mathrm{s}}$ is a vector of the measured absolute accelerations and device displacements in Volts, $\mathbf{y}_{\mathrm{m}}$ is the vector of measured continuous-time absolute accelerations and device displacements in physical units (i.e. $\mathrm{m} / \mathrm{s}^{2}$ for accelerations and $\mathrm{m}$ for displacements), $\mathbf{v}$ is the measurement noise, and

$$
\mathbf{D}_{\mathrm{s}}=\left[\begin{array}{cc}
\mathbf{I}_{14 \times 14} G_{\mathrm{a}} & 0 \\
0 & \mathbf{I}_{8 \times 8} G_{\mathrm{d}}
\end{array}\right]
$$

where $G_{\mathrm{a}}=0.714 \mathrm{Vm}^{-1} \mathrm{~s}^{-2}$ ) is the sensor gain for acceleration and $G_{\mathrm{d}}=30.30 \mathrm{~V} / \mathrm{m}$. The sensor block is represented in the SIMULINK block shown in Figure 9. Note that in the sample controller the device outputs are not measured, and therefore the corresponding signal $\mathbf{y}_{\mathrm{f}}$ is not connected to the system, although it is available for participants to use. The gain block converts the continuous-time acceleration measurements from physical units to Volts. Finally, noise with an rms value of $0.03 \mathrm{~V}$ is included, as is specified in the control constraints, is added to the acceleration signal.

\subsection{Control devices}

A total of 24 hydraulic actuators are employed as control devices and oriented to apply forces longitudinally ( $X$-axis), 8 between the deck and pier 2, 8 between the deck and pier 3, 4 between the deck and bent 1 , and 4 between the deck and pier 4 . Four actuators are located between each of the following pairs of nodes on piers 2 and 3: $(84,313),(151,314),(118,428),(185,429)$; two actuators are located between each of the following pairs of nodes on bent 1 and pier 4: (68, ground), (135, ground), (134, 444), (201, 440). The actuators have a capacity of $1250 \mathrm{kN}$. Figure 10 shows the typical device layout at the tower.

For this sample control design actuator dynamics are neglected and hydraulic actuators are considered to be ideal. The equation governing the dynamics of the longitudinal actuators in the form of Equations $(24,25)$ are

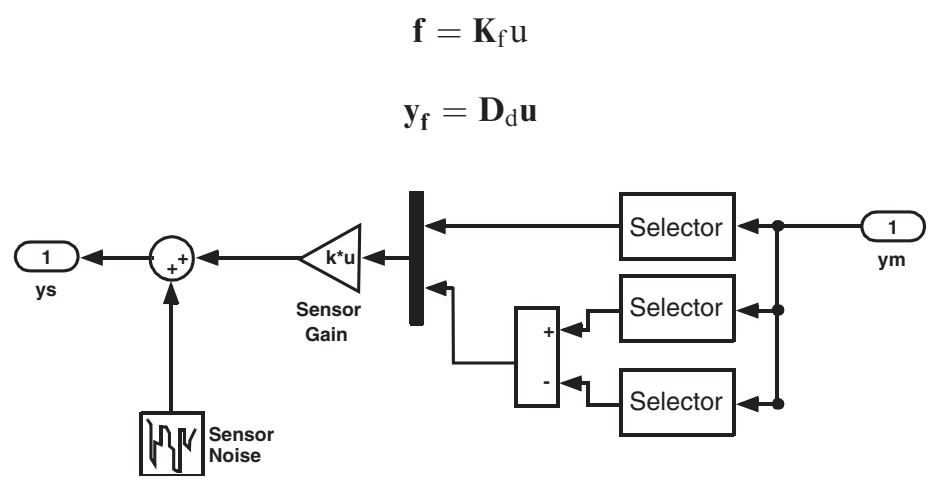

Figure 9. SIMULINK block: sensors. 


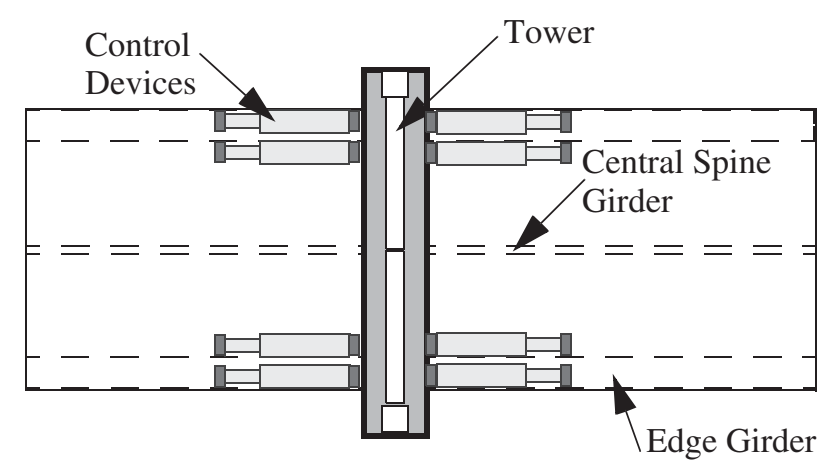

Figure 10. Schematic of control system design: typical tower actuator implementation.

where $\mathbf{D}_{\mathrm{d}}=125 \mathrm{kN} / \mathrm{V}(10 \mathrm{~V}=1250 \mathrm{kN})$ is the gain of the actuator, and $\mathbf{K}_{\mathrm{f}}$ is a matrix that accounts for the gain of the actuator (i.e. the relationship between the input voltage and the desired control force) as well as the fact that multiple actuators are used at each actuator location. For the sample control design $\mathbf{K}_{\mathrm{f}}$ takes the form

$$
\mathbf{K}_{\mathrm{f}}=\left[\begin{array}{ccc}
2 \mathbf{I}_{2 \times 2} & & \mathbf{0} \\
& 4 \mathbf{I}_{4 \times 4} & \\
\mathbf{0} & & 2 \mathbf{I}_{2 \times 2}
\end{array}\right] \mathbf{D}_{\mathrm{d}}=\mathbf{G}_{\mathrm{dev}} \mathbf{D}_{\mathrm{d}}
$$

The vector of forces generated by the devices is

$$
\mathbf{f}=\mathbf{K}_{\mathrm{f}} \mathbf{u}
$$

Figure 11 shows the SIMULINK control device block. For the sample control there are no connection outputs in the model of the devices because the actuator dynamics are neglected and this ideal control device model does not require any inputs from the structure. Connection outputs are available for other type of device implementations.

\subsection{Control design model}

A reduced order model of the system is developed for control design. This model, designated the design model, is formed from the evaluation model and has 60 states. The resulting model has the same outputs as the evaluation model (see Equation 19). The reduced order model is formed in MATLAB by forming a balanced realization of the system and condensing out the states with relatively small controllability and observability grammians. The resulting state space system is represented as follows

$$
\begin{gathered}
\dot{\mathbf{x}}^{\mathrm{r}}=\mathbf{A}_{\mathrm{r}} \mathbf{x}^{\mathrm{r}}+\mathbf{B}_{\mathrm{r}}\left[\begin{array}{c}
\ddot{\mathbf{U}}_{\mathrm{g}} \\
\dot{\mathbf{U}}_{\mathrm{g}}
\end{array}\right]+\mathbf{E}_{\mathrm{r}} \mathbf{u} \\
\mathbf{z}=\mathbf{C}_{\mathrm{r}}^{\mathrm{z}} \mathbf{x}^{\mathrm{r}}+\mathbf{D}_{\mathrm{r}}^{\mathrm{z}}\left[\begin{array}{c}
\ddot{\mathbf{U}}_{\mathrm{g}} \\
\dot{\mathbf{U}}_{\mathrm{g}}
\end{array}\right]+\mathbf{F}_{\mathrm{r}}^{\mathrm{z}} \mathbf{u}
\end{gathered}
$$




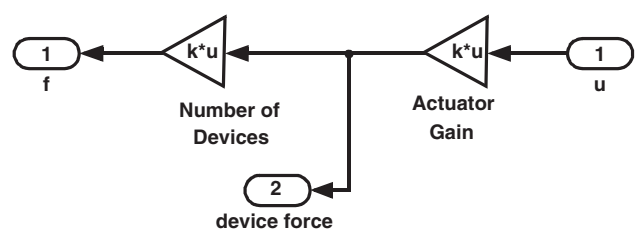

Figure 11. SIMULINK block: control devices.

$$
\mathbf{y}_{\mathrm{m}}=\mathbf{C}_{\mathrm{r}}^{\mathrm{y}} \mathbf{x}^{\mathrm{r}}=\mathbf{D}_{\mathrm{r}}^{\mathrm{y}}\left[\begin{array}{c}
\ddot{\mathbf{U}}_{\mathrm{g}} \\
\dot{\mathbf{U}}_{\mathrm{g}}
\end{array}\right]+\mathbf{F}_{\mathrm{r}}^{\mathrm{y}} \mathbf{u}
$$

where $\mathbf{x}^{\mathrm{r}}$ is the design model state vector, $\mathbf{A}_{\mathrm{r}}$ and $\mathbf{B}_{\mathrm{r}}$ are the system matrices, $\mathbf{z}$ is the regulated output vector, which is obtained from the mapping matrices, $\mathbf{C}_{\mathrm{r}}^{\mathrm{z}}, \mathbf{D}_{\mathrm{r}}^{\mathrm{z}}$ and $\mathbf{F}_{\mathrm{r}}^{\mathrm{z}}$. Similarly, $\mathbf{y}_{\mathrm{m}}$ is the measurement vector, which is obtained from the mapping matrices, $\mathbf{C}_{\mathrm{r}}^{\mathrm{y}}, \mathbf{D}_{\mathrm{r}}^{\mathrm{y}}$ and $\mathbf{F}_{\mathrm{r}}^{\mathrm{y}}$. The gains of the sensors and control devices (i.e. in Equation 49 and $\mathbf{D}_{\mathrm{d}}$ in Equation 52, respectively), as well as the matrix defining the number of control devices $\left(\mathbf{G}_{\mathrm{dev}}\right.$ in Equation 52), are incorporated into this model for control design. Thus, the inputs to the design model are the ground excitation at the base of the structure and the control signals to the devices, whereas the inputs to the evaluation model include the ground excitation and the applied control forces to the structure as in Equation (18).

\subsection{Control algorithm}

The sample controller employs a linear quadratic Gaussian (LQG) control design. For the control system designs, the disturbances to the system (i.e. $\left[\mathbf{U}_{\mathrm{g}}^{\mathrm{T}} \mathbf{U}_{\mathrm{g}}^{\mathrm{T}}\right]^{\mathrm{T}}$ ), are assumed to be identically distributed, statistically independent stationary white noise processes, and $\mathbf{S}_{w}=\mathbf{S}_{w w} \mathbf{I}_{8 \times 8}$, and an infinite horizon performance index is chosen, i.e.

$$
J=\lim _{\tau \rightarrow \infty} \frac{1}{\tau} \mathrm{E}\left[\int_{0}^{\tau}\left\{\left(\mathbf{C}_{\mathrm{r}}^{\mathrm{Z}} \mathbf{x}^{\mathrm{r}}+\mathbf{D}_{\mathrm{r}}^{\mathrm{z}} \mathbf{u}\right)^{\mathrm{T}} Q\left(\mathbf{C}_{\mathrm{r}}^{\mathrm{z}} \mathbf{x}^{\mathrm{r}}+\mathbf{D}_{\mathrm{r}}^{\mathrm{z}} \mathbf{u}\right)+\mathbf{u}^{\mathrm{T}} \mathbf{R} \mathbf{u}\right\}\right]
$$

where $\mathbf{R}$ is an identity matrix. The control algorithm is designed by choosing a performance index that weights the displacements of the deck at bent 1 and pier 4 , with $\mathrm{q}_{1}=3.5 \times 10^{3}$. The performance index that weights the translational acceleration at mid-span is $q_{2}=3.5 \times 10^{2}$. The weighting matrix $\mathbf{Q}$ is defined as

$$
\mathbf{Q}=\left[\begin{array}{cc}
\mathrm{q}_{1} \mathrm{I}_{4 \times 4} & 0 \\
0 & \mathrm{q}_{2}
\end{array}\right]
$$

$\mathbf{R}$ is an [ $8 \times 8]$ identity matrix. Further, for each case, the measurement noise is assumed to be identically distributed, statistically independent Gaussian white noise processes, and $S_{w w} / S_{v_{i} v_{i}}=$ $\gamma=25$.

The control and estimation problems are considered separately according to the separation principle [20, 21], yielding a controller of the form

$$
\mathbf{u}=-\mathbf{K}_{\mathbf{u}} \hat{\mathbf{x}}^{\mathrm{r}}
$$

where $\hat{\mathbf{x}}^{\mathrm{r}}$ is the Kalman filter estimate of the state vector based on the reduced order model. By the certainty equivalence principle $[20,21], \mathbf{K}_{\mathbf{u}}$ is the full-state feedback gain matrix for the 
deterministic regulator problem given by

$$
\mathbf{K}_{\mathbf{u}}=\tilde{\mathbf{R}}^{-1}\left(\tilde{\mathbf{N}}+\mathbf{B}_{\mathrm{d}}^{\mathrm{T}} \underset{\sim}{\mathbf{P}}\right)
$$

where $\underset{\sim}{\mathbf{P}}$ is the solution of the algebraic Riccati equation given by

$$
\mathbf{0}=\underset{\sim}{\mathbf{P}} \tilde{A}+\tilde{\mathbf{A}}^{\mathrm{T}} \underset{\sim}{\mathbf{P}}-\underset{\sim}{\mathbf{P}} B_{\mathrm{d}} \tilde{\mathbf{R}}^{-1} \mathbf{B}_{\mathrm{d}}^{\mathrm{T}} \underset{\sim}{\mathbf{P}}+\tilde{\mathbf{Q}}
$$

and

$$
\begin{gathered}
\tilde{\mathbf{Q}}=\mathbf{C}_{\mathrm{d}}^{\mathrm{zT}} \mathbf{Q} \mathbf{C}_{\mathrm{d}}^{\mathrm{z}}-\tilde{\mathbf{N}} \tilde{\mathbf{R}}^{-1} \tilde{\mathbf{N}}^{\mathrm{T}} \\
\tilde{\mathbf{N}}=\mathbf{C}_{\mathrm{d}}^{\mathrm{zT}} \mathbf{Q} \mathbf{D}_{\mathrm{d}}^{\mathrm{z}} \\
\tilde{\mathbf{R}}=\mathbf{R}+\mathbf{D}_{\mathrm{d}}^{\mathrm{zT}} \mathbf{Q} \mathbf{D}_{\mathrm{d}}^{\mathrm{z}} \\
\tilde{\mathbf{A}}=\mathbf{A}_{\mathrm{d}}-\mathbf{B}_{\mathrm{d}} \tilde{\mathbf{R}}^{-1} \tilde{\mathbf{N}}^{\mathrm{T}}
\end{gathered}
$$

Calculations to determine $\mathbf{K}_{\mathbf{u}}$ were done using the MATLAB [11] routine lqry. $m$ within the control toolbox.

The Kalman filter optimal estimator is given by

$$
\begin{gathered}
\dot{\hat{\mathbf{x}}}^{\mathrm{r}}=\mathbf{A}_{\mathrm{r}} \hat{\mathbf{x}}^{\mathrm{r}}+\mathbf{B}_{\mathrm{r}} \mathbf{u}+\mathbf{L}\left(\mathbf{y}_{\mathrm{m}}-\mathbf{C}_{\mathrm{r}}^{\mathrm{y}} \hat{\mathbf{x}}^{\mathrm{r}}-\mathbf{D}_{\mathrm{r}}^{\mathrm{y}} \mathbf{u}\right) \\
\mathbf{L}=\left[{\underset{\sim}{\mathbf{R}}}^{-1}\left(\gamma \mathbf{F}_{\mathrm{r}}^{\mathrm{y}} \mathbf{E}_{\mathrm{r}}^{\mathrm{T}}+\mathbf{C}_{\mathrm{r}}^{\mathrm{y}} \mathbf{S}\right)\right]^{\mathrm{T}}
\end{gathered}
$$

where $\mathbf{S}$ is the solution of the algebraic Riccati equation given by

$$
\mathbf{0}=\mathbf{S} \underset{\sim}{\mathbf{A}}=\underset{\sim}{\mathbf{A}}{ }^{\mathrm{T}} \mathbf{S}-\mathbf{S G} S+\underset{\sim}{\mathbf{H}}
$$

and

$$
\begin{aligned}
& \underset{\sim}{\mathbf{A}}=\mathbf{A}_{\mathrm{r}}^{\mathrm{T}}-\mathbf{C}_{\mathrm{r}}^{\mathrm{yT}} \stackrel{\sim}{\mathbf{R}}^{-1}\left(\gamma \mathbf{F}_{\mathrm{r}}^{\mathrm{y}} \mathbf{E}_{\mathrm{r}}^{\mathrm{yT}}\right) \\
& \underset{\sim}{\mathbf{G}}=\mathbf{C}_{\mathrm{r}}^{\mathrm{yT}}{\underset{\sim}{\mathbf{R}}}^{-1} \mathbf{C}_{\mathrm{r}}^{\mathrm{y}} \\
& \underset{\sim}{\mathbf{H}}=\gamma \mathbf{E}_{\mathrm{r}} \mathbf{E}_{\mathrm{r}}^{\mathrm{T}}-\gamma^{2} \mathbf{E}_{\mathrm{r}} \mathbf{F}_{\mathrm{r}}^{\mathrm{y}}{\underset{\sim}{\mathrm{T}}}^{-1} \mathbf{F}_{\mathrm{r}}^{\mathrm{y}} \mathbf{E}_{\mathrm{r}}^{\mathrm{T}} \\
& \underset{\sim}{\mathbf{R}}=\mathbf{I}+\gamma \mathbf{F}_{\mathrm{r}}^{\mathrm{y}} \mathbf{F}_{\mathrm{r}}^{\mathrm{yT}}
\end{aligned}
$$

Calculations to determine $\mathbf{L}$ were done using the MATLAB routine lqew. $m$ within the control toolbox.

For implementation on a digital computer, the controller is put in the form of Equations $(22,23)$ using the bilinear transformation [22] to yield the following compensator

$$
\begin{gathered}
\mathbf{x}_{k+1}^{\mathrm{c}}=\mathbf{A}_{\mathrm{c}} \mathbf{x}_{k}^{\mathrm{c}}+\mathbf{B}_{\mathrm{c}} \mathbf{y}_{k}^{\mathrm{s}} \\
\mathbf{u}_{k}=\mathbf{C}_{\mathrm{c}} \mathbf{x}_{k}^{\mathrm{c}}+\mathbf{D}_{\mathrm{c}} \mathbf{y}_{\mathrm{k}}^{\mathrm{s}} .
\end{gathered}
$$

Calculations to determine the discrete-time compensator were performed in MATLAB using the $c 2 d m . m$ routine within the control toolbox. 
The SIMULINK block shown in Figure 12 is used to represent the sample control algorithm in the simulation. To represent the hardware used to implement this algorithm on a digital computer, the input signal passes through a model of an analog-to-digital converter (A/D) and the output control signal passes through a model of a digital-to-analog converter $(\mathrm{D} / \mathrm{A})$. The model consists of a quantizer and a saturator as described in Section 5.4.

\subsection{Evaluation of sample control design}

The closed-loop response is evaluated for the three earthquakes specified. Table II shows the values of the evaluation criteria in Equations (29-47). The responses of the controlled bridge are compared with those of the uncontrolled bridge for the El Centro and Mexico City earthquakes in Figures 13 and 14. In each figure, the left-hand plots show the maximum and minimum cable tension as a function of cable number. The dark region provides the acceptable range of cable tensions as specified in the control constraints (between the $0.2 T_{\mathrm{f} i}$ and $0.7 T_{\mathrm{f} i}$ ), and the lighter region provides a graphical description of the actual minimum and maximum cable tension. Note that the uncontrolled cable tension falls below the lower bound in cables near the tower when subjected to the El Centro earthquake. However, in each case the controlled cable tension

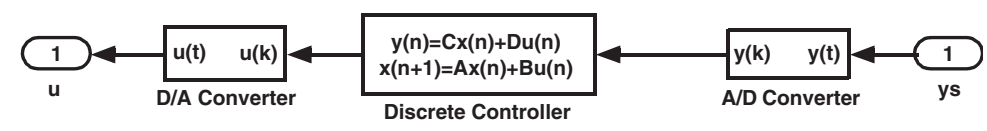

Figure 12. SIMULINK block: control algorithm.

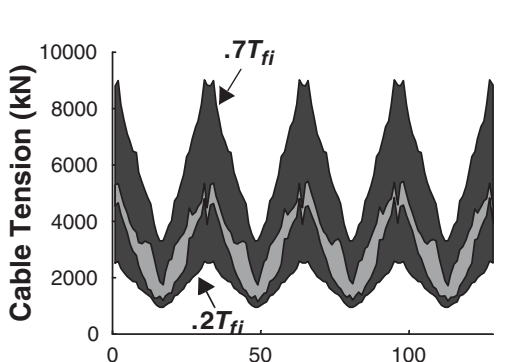

(a)

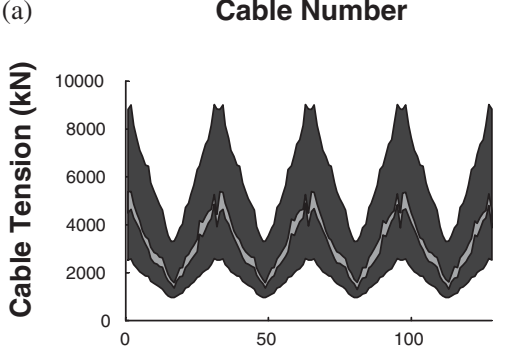

(b)

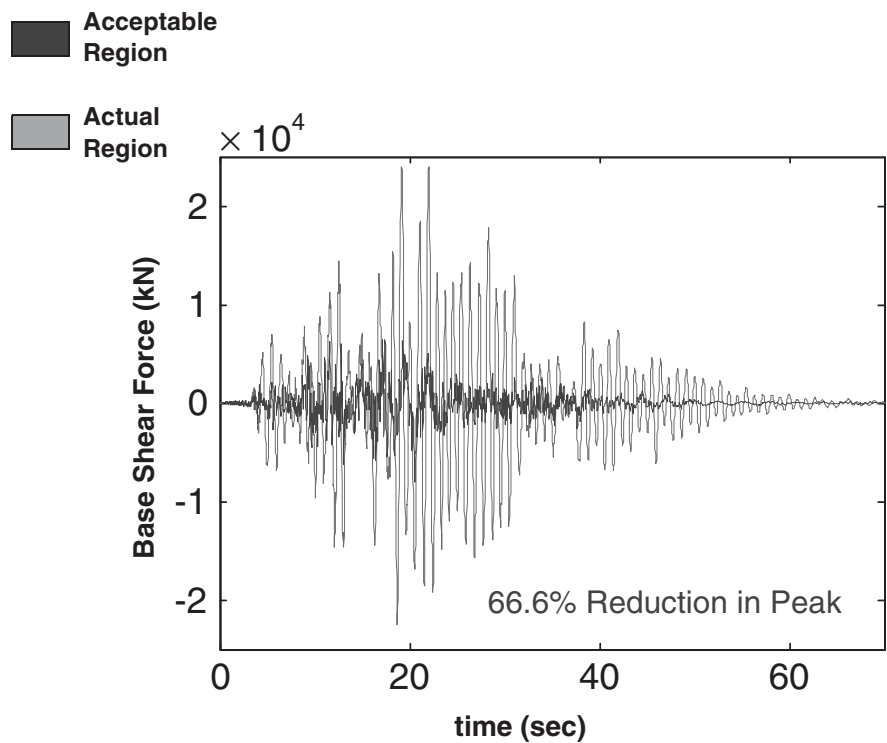

(c)

Figure 13. Simulated responses to Mexico City earthquake (no snow, case A): (a) uncontrolled cable tensions; (b) controlled cable tensions; (c) uncontrolled and controlled base shear force record (pier 2). 

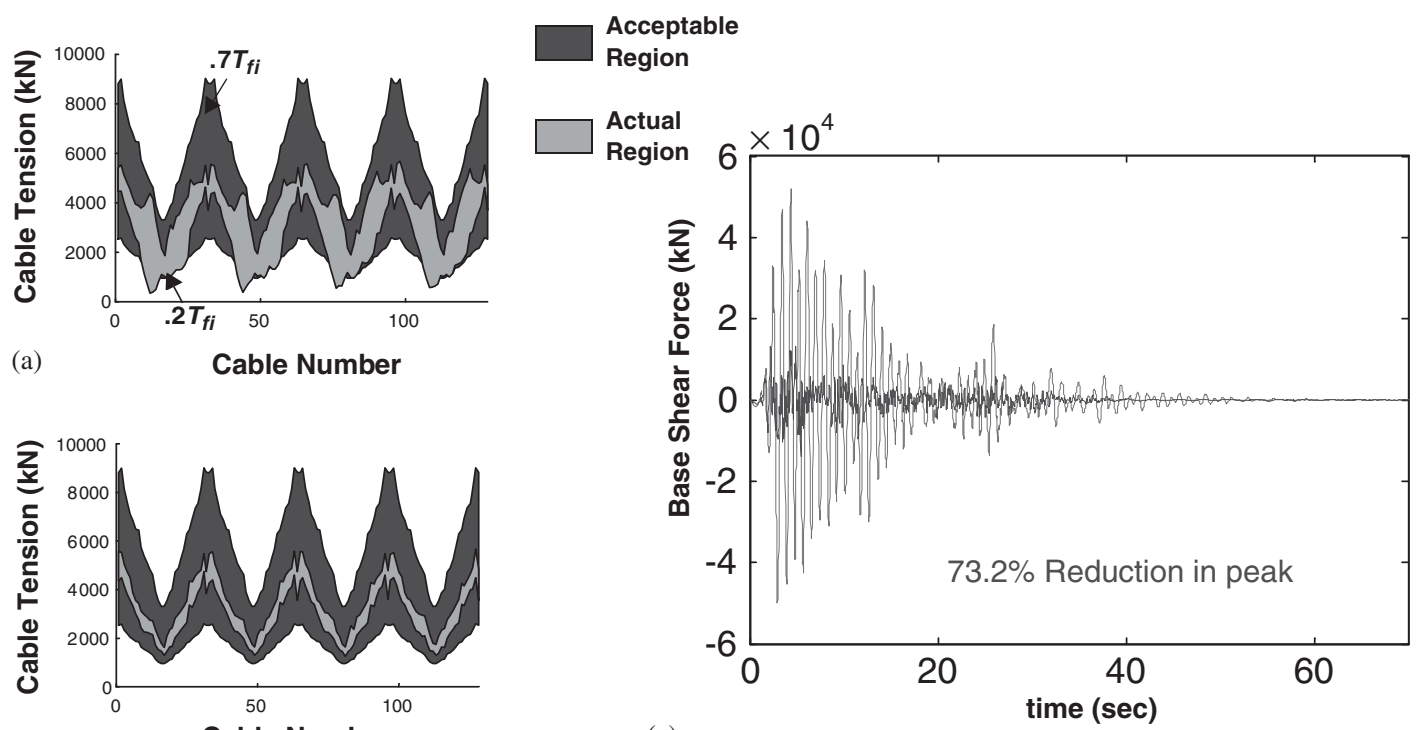

(b)

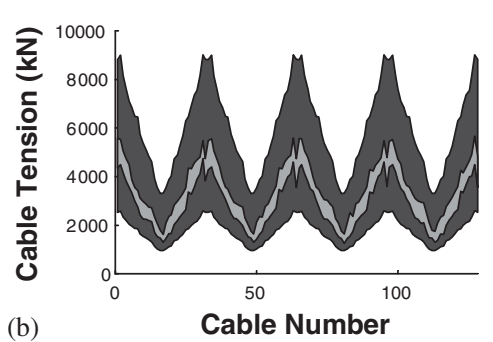

(c)

Figure 14. Simulated responses to El Centro earthquake (no snow, case A): (a) uncontrolled cable tensions; (b) controlled cable tensions; (c) uncontrolled and controlled base shear force record (Pier 2).

is well within the bounds. Additionally each figure provides a graph of the base shear at pier 2 in the longitudinal direction. Note that the controller is able to achieve a significant reduction in the base shear forces as compared with the uncontrolled system.

To demonstrate the feasibility of this controller, peak values of the force, stroke, and velocity are provided for each earthquake in Table IV. Note that the force requirement as well as the velocity and displacement requirements are feasible in a device of this size.

\section{CLOSURE}

A second-generation benchmark problem on the seismic control of cable-stayed bridges has been developed. Phase II of this benchmark problem extends the problem to consider ground motions with two horizontal components, as well as multi-support excitation. The evaluation model of the Bill Emerson Memorial Bridge, the MATLAB files used for the sample control design, and the simulation model, are available at: http://wusceel.cive.wustl.edu/quake/

If you cannot access the World Wide Web or have questions regarding the benchmark problem please contact Dr Shirley Dyke via e-mail at: sdyke@seas.wustl.edu. Participants in the benchmark study will be expected to submit their control designs and supporting MATLAB files electronically for inclusion on the benchmark homepage, as described in the information distributed with the benchmark cable-stayed bridge problem.

\section{APPENDIX}

Tables I-VII 


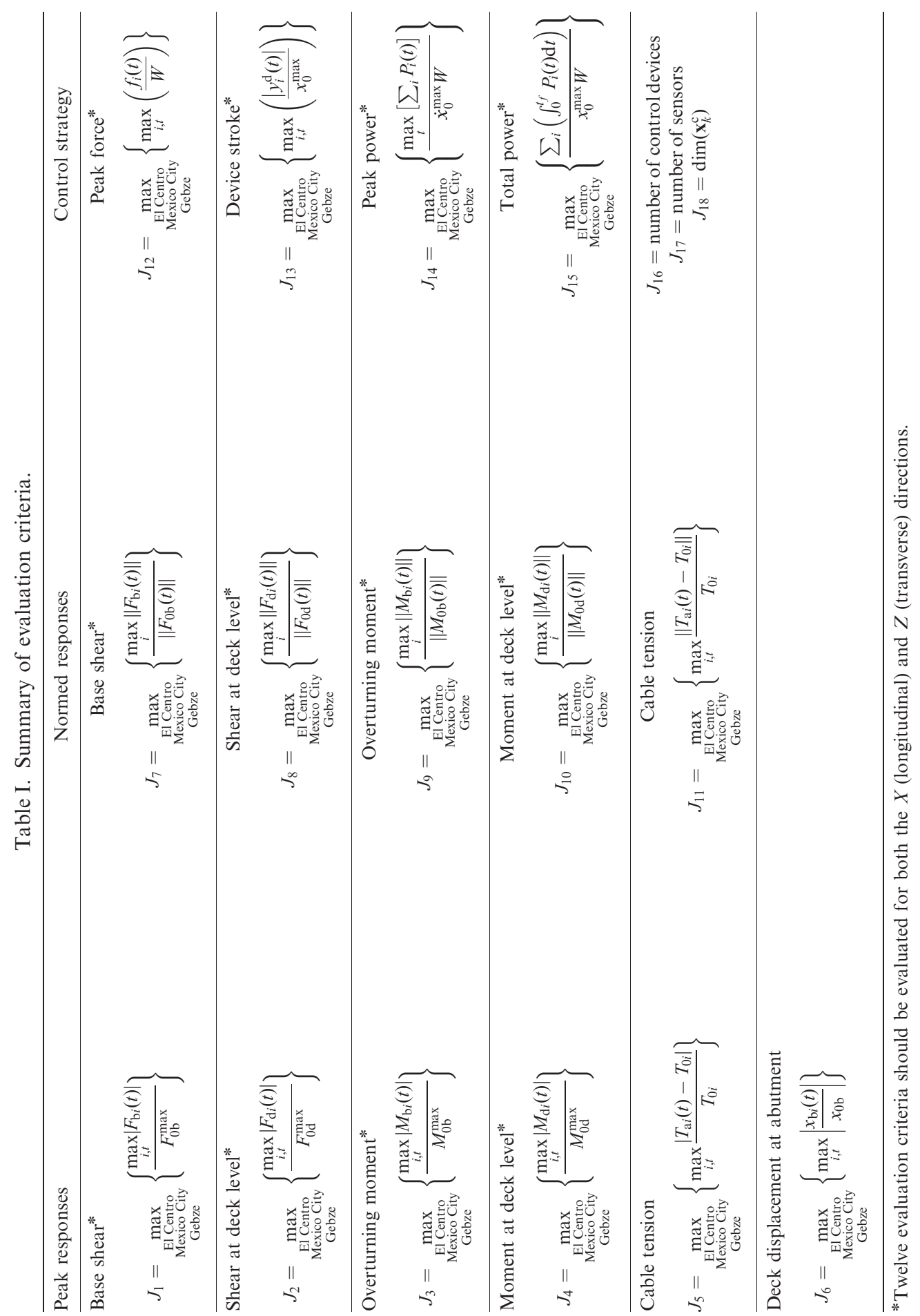


Table II. Evaluation criteria for sample controller.

\begin{tabular}{|c|c|c|c|c|c|}
\hline Value & Direction & El Centro & Mexico & Gebze & Maximum \\
\hline \multicolumn{6}{|c|}{ Case A $(0,0.05,0.16,0.20) \mathrm{s}$ at $15^{\circ}$} \\
\hline \multirow[t]{2}{*}{$J_{1}$} & $X$ & 0.3008 & 0.3826 & 0.4672 & 0.4672 \\
\hline & $Z$ & 1.0215 & 1.1168 & 1.0366 & 1.1168 \\
\hline \multirow[t]{2}{*}{$J_{2}$} & $X$ & 0.7529 & 0.9092 & 0.9748 & 0.9748 \\
\hline & $Z$ & 0.9662 & 0.9981 & 0.9963 & 0.9981 \\
\hline \multirow[t]{2}{*}{$J_{3}$} & $X$ & 0.3288 & 0.3734 & 0.4540 & 0.4540 \\
\hline & $Z$ & 1.0978 & 1.0796 & 1.0463 & 1.0978 \\
\hline \multirow[t]{2}{*}{$J_{4}$} & $X$ & 0.5790 & 0.7601 & 0.9238 & 0.9238 \\
\hline & $Z$ & 1.0097 & 0.9930 & 1.0012 & 1.0097 \\
\hline$J_{5}$ & $X$ & 0.2557 & 0.1355 & 0.1782 & 0.2557 \\
\hline$J_{6}$ & $X$ & 1.0489 & 1.7787 & 2.3270 & 2.3270 \\
\hline \multirow[t]{2}{*}{$J_{7}$} & $X$ & 0.2483 & 0.3054 & 0.3149 & 0.3149 \\
\hline & $Z$ & 1.0136 & 1.0554 & 1.0529 & 1.0554 \\
\hline \multirow[t]{2}{*}{$J_{8}$} & $X$ & 0.8329 & 0.9046 & 0.9635 & 0.9635 \\
\hline & $Z$ & 0.9783 & 0.9961 & 0.9912 & 0.9961 \\
\hline \multirow[t]{2}{*}{$J_{9}$} & $X$ & 0.2420 & 0.3163 & 0.3966 & 0.3966 \\
\hline & $Z$ & 1.0053 & 1.0520 & 1.0394 & 1.0520 \\
\hline \multirow[t]{2}{*}{$J_{10}$} & $X$ & 0.6232 & 0.7968 & 0.8245 & 0.8245 \\
\hline & $Z$ & 1.0018 & 1.0044 & 1.0033 & 1.0044 \\
\hline$J_{11}$ & - & $2.404 \times 10^{-2}$ & $1.443 \times 10^{-2}$ & $1.684 \times 10^{-2}$ & $2.404 \times 10^{-2}$ \\
\hline \multirow[t]{2}{*}{$J_{12}$} & $X$ & $2.883 \times 10^{-3}$ & $1.636 \times 10^{-3}$ & $2.844 \times 10^{-3}$ & $2.883 \times 10^{-3}$ \\
\hline & $Z$ & 00 & 0 & 0 & 0 \\
\hline \multirow[t]{2}{*}{$J_{13}$} & $X$ & 0.6425 & 0.9686 & 1.0154 & 1.0154 \\
\hline & $Z$ & 0 & 0 & 0 & 0 \\
\hline \multirow[t]{2}{*}{$J_{14}$} & $X$ & $3.532 \times 10^{-3}$ & $2.334 \times 10^{-3}$ & $6.896 \times 10^{-3}$ & $6.896 \times 10^{-3}$ \\
\hline & $Z$ & 0 & 0 & 0 & 0 \\
\hline \multirow[t]{2}{*}{$J_{15}$} & $X$ & $5.201 \times 10^{-4}$ & $3.395 \times 10^{-4}$ & $6.809 \times 10^{-4}$ & $6.809 \times 10^{-4}$ \\
\hline & $Z$ & 0 & 0 & 0 & 0 \\
\hline$J_{16}$ & - & 24 & 24 & 24 & 24 \\
\hline$J_{17}$ & - & 14 & 14 & 14 & 14 \\
\hline$J_{18}$ & - & 60 & 60 & 60 & 60 \\
\hline \multicolumn{6}{|c|}{ Case $\mathrm{B}(0,0.03,0.12,0.15) \mathrm{s}$ at $45^{\circ}$} \\
\hline \multirow[t]{2}{*}{$J_{1}$} & $X$ & 0.3478 & 0.3703 & 0.4267 & 0.4267 \\
\hline & $Z$ & 0.9905 & 1.0432 & 0.9977 & 1.0432 \\
\hline \multirow[t]{2}{*}{$J_{2}$} & $X$ & 0.7169 & 1.0068 & 0.9837 & 1.0068 \\
\hline & $Z$ & 0.9843 & 0.9696 & 0.9903 & 0.9903 \\
\hline \multirow[t]{2}{*}{$J_{3}$} & $X$ & 0.3850 & 0.3849 & 0.4896 & 0.4896 \\
\hline & $Z$ & 0.9790 & 1.0288 & 0.9924 & 1.0288 \\
\hline \multirow[t]{2}{*}{$J_{4}$} & $X$ & 0.6001 & 0.6588 & 0.7731 & 0.7731 \\
\hline & $Z$ & 0.9969 & 1.0006 & 1.0022 & 1.0022 \\
\hline$J_{5}$ & - & 0.2865 & 0.1363 & 0.1956 & 0.2865 \\
\hline$J_{6}$ & $X$ & 1.2524 & 2.1208 & 2.6391 & 2.6391 \\
\hline$J_{7}$ & $X$ & 0.2598 & 0.3327 & 0.3514 & 0.3514 \\
\hline & $Z$ & 0.9822 & 1.0029 & 1.0253 & 1.0253 \\
\hline$J_{8}$ & $X$ & 0.8244 & 0.9145 & 0.9957 & 0.9957 \\
\hline & $Z$ & 0.9922 & 0.9718 & 1.0015 & 1.0015 \\
\hline$J_{9}$ & $X$ & 0.2584 & 0.3463 & 0.4693 & 0.4693 \\
\hline & $Z$ & 0.9855 & 0.9975 & 1.0221 & 1.0221 \\
\hline$J_{10}$ & $X$ & 0.6743 & 0.8465 & 0.9632 & 0.9632 \\
\hline & $Z$ & 1.0033 & 1.0033 & 1.0049 & 1.0049 \\
\hline$J_{11}$ & - & $2.637 \times 10^{-2}$ & $1.459 \times 10^{-2}$ & $1.774 \times 10^{-2}$ & $2.637 \times 10^{-2}$ \\
\hline$J_{12}$ & $X$ & $2.587 \times 10^{-3}$ & $1.690 \times 10^{-3}$ & $2.268 \times 10^{-3}$ & $2.587 \times 10^{-3}$ \\
\hline & $Z$ & 0 & 0 & 0 & 0 \\
\hline$J_{13}$ & $X$ & 0.6643 & 0.9713 & 1.1719 & 1.1719 \\
\hline & $Z$ & 0 & 0 & 0 & 0 \\
\hline
\end{tabular}


Table II. Continued.

\begin{tabular}{lccccc}
\hline Value & Direction & El Centro & Mexico & Gebze & Maximum \\
\hline \multicolumn{7}{c}{ Case B $(0,0.03,0.12,0.15) \mathrm{s}$ at $45^{\circ}$} \\
\hline$J_{14}$ & $X$ & $3.613 \times 10^{-3}$ & $2.955 \times 10^{-3}$ & $4.822 \times 10^{-3}$ & $4.822 \times 10^{-3}$ \\
$J_{15}$ & $Z$ & 0 & 0 & 0 & 0 \\
& $X$ & $4.596 \times 10^{-4}$ & $3.728 \times 10^{-4}$ & $5.344 \times 10^{-4}$ & $5.344 \times 10^{-4}$ \\
$J_{16}$ & $Z$ & 0 & 0 & 0 & 0 \\
$J_{17}$ & - & 24 & 24 & 24 & 14 \\
$J_{18}$ & - & 14 & 60 & 60 & 60 \\
\hline
\end{tabular}

Table III. Evaluation criteria for sample controller with snow loads.

\begin{tabular}{|c|c|c|c|c|c|}
\hline Value & Direction & El Centro & Mexico & Gebze & Maximum \\
\hline \multicolumn{6}{|c|}{ Case A $[0,0.05,0.16,0.20] \mathrm{s}$ at $15^{\circ} \mathrm{C}$} \\
\hline \multirow{2}{*}{$J_{1}$} & $X$ & 0.3411 & 0.4308 & 0.4728 & 0.4728 \\
\hline & $Z$ & 1.0214 & 1.1152 & 1.0367 & 1.1152 \\
\hline \multirow{2}{*}{$J_{2}$} & $X$ & 0.7909 & 0.9340 & 1.0145 & 1.0145 \\
\hline & $Z$ & 0.9658 & 0.9984 & 0.9964 & 0.9984 \\
\hline \multirow{2}{*}{$J_{3}$} & $X$ & 0.3395 & 0.4101 & 0.4569 & 0.4569 \\
\hline & $Z$ & 1.0964 & 1.0936 & 1.0460 & 1.0964 \\
\hline \multirow[t]{2}{*}{$J_{4}$} & $X$ & 0.6014 & 0.7685 & 0.9482 & 0.9482 \\
\hline & $Z$ & 1.0099 & 0.9934 & 1.0012 & 1.0099 \\
\hline$J_{5}$ & $X$ & 0.2494 & 0.1243 & 0.1771 & 0.2494 \\
\hline$J_{6}$ & $X$ & 1.0726 & 1.7988 & 2.4286 & 2.4286 \\
\hline \multirow[t]{2}{*}{$J_{7}$} & $X$ & 0.2867 & 0.3599 & 0.3199 & 0.3599 \\
\hline & $Z$ & 1.0135 & 1.0551 & 1.0529 & 1.0551 \\
\hline \multirow[t]{2}{*}{$J_{8}$} & $X$ & 0.8480 & 0.9038 & 0.9874 & 0.9874 \\
\hline & $Z$ & 0.9787 & 0.9967 & 0.9912 & 0.9967 \\
\hline \multirow[t]{2}{*}{$J_{9}$} & $X$ & 0.2534 & 0.3376 & 0.4092 & 0.4092 \\
\hline & $Z$ & 1.0053 & 1.0519 & 1.0394 & 1.0519 \\
\hline \multirow[t]{2}{*}{$J_{10}$} & $X$ & 0.6274 & 0.8032 & 0.8495 & 0.8495 \\
\hline & $Z$ & 1.0019 & 1.0043 & 1.0033 & 1.0043 \\
\hline$J_{11}$ & - & $2.353 \times 10^{-2}$ & $1.449 \times 10^{-2}$ & $1.766 \times 10^{-2}$ & $2.353 \times 10^{-2}$ \\
\hline \multirow{2}{*}{$J_{12}$} & $X$ & $2.941 \times 10^{-3}$ & $1.717 \times 10^{-3}$ & $2.941 \times 10^{-3}$ & $2.941 \times 10^{-3}$ \\
\hline & $Z$ & 0 & 0 & 0 & 0 \\
\hline \multirow[t]{2}{*}{$J_{13}$} & $X$ & 0.6640 & 0.9986 & 1.0597 & 1.0597 \\
\hline & $Z$ & 0 & 0 & 0 & 0 \\
\hline \multirow[t]{2}{*}{$J_{14}$} & $X$ & $4.090 \times 10^{-3}$ & $2.576 \times 10^{-3}$ & $7.371 \times 10^{-3}$ & $7.371 \times 10^{-3}$ \\
\hline & $Z$ & 0 & 0 & 0 & 0 \\
\hline \multirow[t]{2}{*}{$J_{15}$} & $X$ & $6.033 \times 10^{-4}$ & $3.765 \times 10^{-4}$ & $7.278 \times 10^{-4}$ & $7.278 \times 10^{-4}$ \\
\hline & $Z$ & 0 & 0 & 0 & 0 \\
\hline$J_{16}$ & - & 24 & 24 & 24 & 24 \\
\hline$J_{17}$ & - & 14 & 14 & 14 & 14 \\
\hline$J_{18}$ & - & 60 & 60 & 60 & 60 \\
\hline \multicolumn{6}{|c|}{ Case $\mathrm{B}[0,0.03,0.12,0.15] \mathrm{s}$ at $45^{\circ}$} \\
\hline \multirow[t]{2}{*}{$J_{1}$} & $X$ & 0.4341 & 0.4375 & 0.4293 & 0.4375 \\
\hline & $Z$ & 0.9869 & 1.0349 & 0.9976 & 1.0349 \\
\hline \multirow[t]{2}{*}{$J_{2}$} & $X$ & 0.6904 & 1.0021 & 1.0085 & 1.0085 \\
\hline & $Z$ & 0.9825 & 0.9738 & 0.9904 & 0.9904 \\
\hline \multirow[t]{2}{*}{$J_{3}$} & $X$ & 0.4051 & 0.4277 & 0.4982 & 0.4982 \\
\hline & $Z$ & 0.9800 & 1.0290 & 0.9923 & 1.0290 \\
\hline \multirow[t]{2}{*}{$J_{4}$} & $X$ & 0.6177 & 0.6551 & 0.7968 & 0.7968 \\
\hline & $Z$ & 0.9970 & 1.0001 & 1.0022 & 1.0022 \\
\hline
\end{tabular}


Table III. Continued.

\begin{tabular}{|c|c|c|c|c|c|}
\hline Value & Direction & El Centro & Mexico & Gebze & Maximum \\
\hline \multicolumn{6}{|c|}{ Case B $[0,0.03,0.12,0.15] \mathrm{s}$ at $45^{\circ}$} \\
\hline$J_{5}$ & - & 0.2801 & 0.1289 & 0.1882 & 0.2801 \\
\hline$J_{6}$ & $X$ & 1.2644 & 2.1379 & 2.7525 & 2.7525 \\
\hline \multirow[t]{2}{*}{$J_{7}$} & $X$ & 0.3035 & 0.3934 & 0.3588 & 0.3934 \\
\hline & $Z$ & 0.9826 & 1.0026 & 1.0254 & 1.0254 \\
\hline \multirow[t]{2}{*}{$J_{8}$} & $X$ & 0.8382 & 0.9328 & 1.0151 & 1.0151 \\
\hline & $Z$ & 0.9922 & 0.9719 & 1.0016 & 1.0016 \\
\hline \multirow[t]{2}{*}{$J_{9}$} & $X$ & 0.2719 & 0.3706 & 0.4852 & 0.4852 \\
\hline & $Z$ & 0.9856 & 0.9974 & 1.0222 & 1.0222 \\
\hline \multirow[t]{2}{*}{$J_{10}$} & $X$ & 0.6781 & 0.8578 & 0.9911 & 0.9911 \\
\hline & $Z$ & 1.0033 & 1.0033 & 1.0049 & 1.0049 \\
\hline$J_{11}$ & - & $2.588 \times 10^{-2}$ & $1.466 \times 10^{-2}$ & $1.776 \times 10^{-2}$ & $2.588 \times 10^{-2}$ \\
\hline \multirow[t]{2}{*}{$J_{12}$} & $X$ & $2.783 \times 10^{-3}$ & $1.761 \times 10^{-3}$ & $2.414 \times 10^{-3}$ & $2.783 \times 10^{-3}$ \\
\hline & $Z$ & 0 & 0 & 0 & 0 \\
\hline \multirow[t]{2}{*}{$J_{13}$} & $X$ & 0.6614 & 0.9957 & 1.2223 & 1.2223 \\
\hline & $Z$ & 0 & 0 & 0 & 0 \\
\hline \multirow[t]{2}{*}{$J_{14}$} & $X$ & $4.103 \times 10^{-3}$ & $3.206 \times 10^{-3}$ & $5.310 \times 10^{-3}$ & $5.310 \times 10^{-3}$ \\
\hline & $Z$ & 0 & 0 & 0 & 0 \\
\hline \multirow[t]{2}{*}{$J_{15}$} & $X$ & $5.128 \times 10^{-4}$ & $4.087 \times 10^{-4}$ & $5.885 \times 10^{-4}$ & $5.885 \times 10^{-4}$ \\
\hline & $Z$ & 0 & 0 & 0 & 0 \\
\hline$J_{16}$ & - & 24 & 24 & 24 & 24 \\
\hline$J_{17}$ & - & 14 & 14 & 14 & 14 \\
\hline$J_{18}$ & - & 60 & 60 & 60 & 60 \\
\hline
\end{tabular}

Table IV. Maximum actuator requirements for sample control strategy.

\begin{tabular}{|c|c|c|c|c|c|}
\hline Response & Direction & El Centro & Mexico & Gebze & Maximum \\
\hline \multicolumn{6}{|c|}{ Case A $[0,0.05,0.16,0.20] \mathrm{s}$ at $15^{\circ}$} \\
\hline Force $(\mathrm{kN})$ & $\mathrm{Z}$ & 1470.145 & 834.389 & 1450.378 & 1470.145 \\
\hline Stroke (m) & $\mathrm{Z}$ & 0.106 & 0.093 & 0.162 & 0.162 \\
\hline Vel $(\mathrm{m} / \mathrm{s})$ & $\mathrm{Z}$ & 0.811 & 0.402 & 0.535 & 0.811 \\
\hline \multicolumn{6}{|c|}{ Case B $[0,0.03,0.12,0.15] \mathrm{s}$ at $45^{\circ}$} \\
\hline Force $(\mathrm{kN})$ & $\mathrm{Z}$ & 1319.488 & 862.081 & 1156.693 & 1319.488 \\
\hline Stroke (m) & $\mathrm{Z}$ & 0.120 & 0.094 & 0.148 & 0.148 \\
\hline $\operatorname{Vel}(\mathrm{m} / \mathrm{s})$ & $\mathrm{Z}$ & 0.636 & 0.456 & 0.457 & 0.636 \\
\hline
\end{tabular}

Table V. Maximum actuator requirements for sample control strategy with snow loads.

\begin{tabular}{|c|c|c|c|c|c|}
\hline Response & Direction & El Centro & Mexico & Gebze & Maximum \\
\hline \multicolumn{6}{|c|}{ Case A $[0,0.05,0.16,0.20] \mathrm{s}$ at $15^{\circ}$} \\
\hline Force $(\mathrm{kN})$ & $\mathrm{Z}$ & 1500.000 & 875.727 & 1500.000 & 1500.000 \\
\hline Stroke $(\mathrm{m})$ & $\mathrm{Z}$ & 0.108 & 0.095 & 0.169 & 0.169 \\
\hline $\operatorname{Vel}(\mathrm{m} / \mathrm{s})$ & $\mathrm{Z}$ & 0.825 & 0.403 & 0.543 & 0.825 \\
\hline \multicolumn{6}{|c|}{ Case B $[0,0.03,0.12,0.15] \mathrm{s}$ at $45^{\circ}$} \\
\hline Force $(\mathrm{kN})$ & $\mathrm{Z}$ & 1419.342 & 897.910 & 1231.341 & 1419.342 \\
\hline Stroke (m) & $\mathrm{Z}$ & 0.121 & 0.095 & 0.155 & 0.155 \\
\hline $\operatorname{Vel}(\mathrm{m} / \mathrm{s})$ & $\mathrm{Z}$ & 0.645 & 0.454 & 0.467 & 0.645 \\
\hline
\end{tabular}




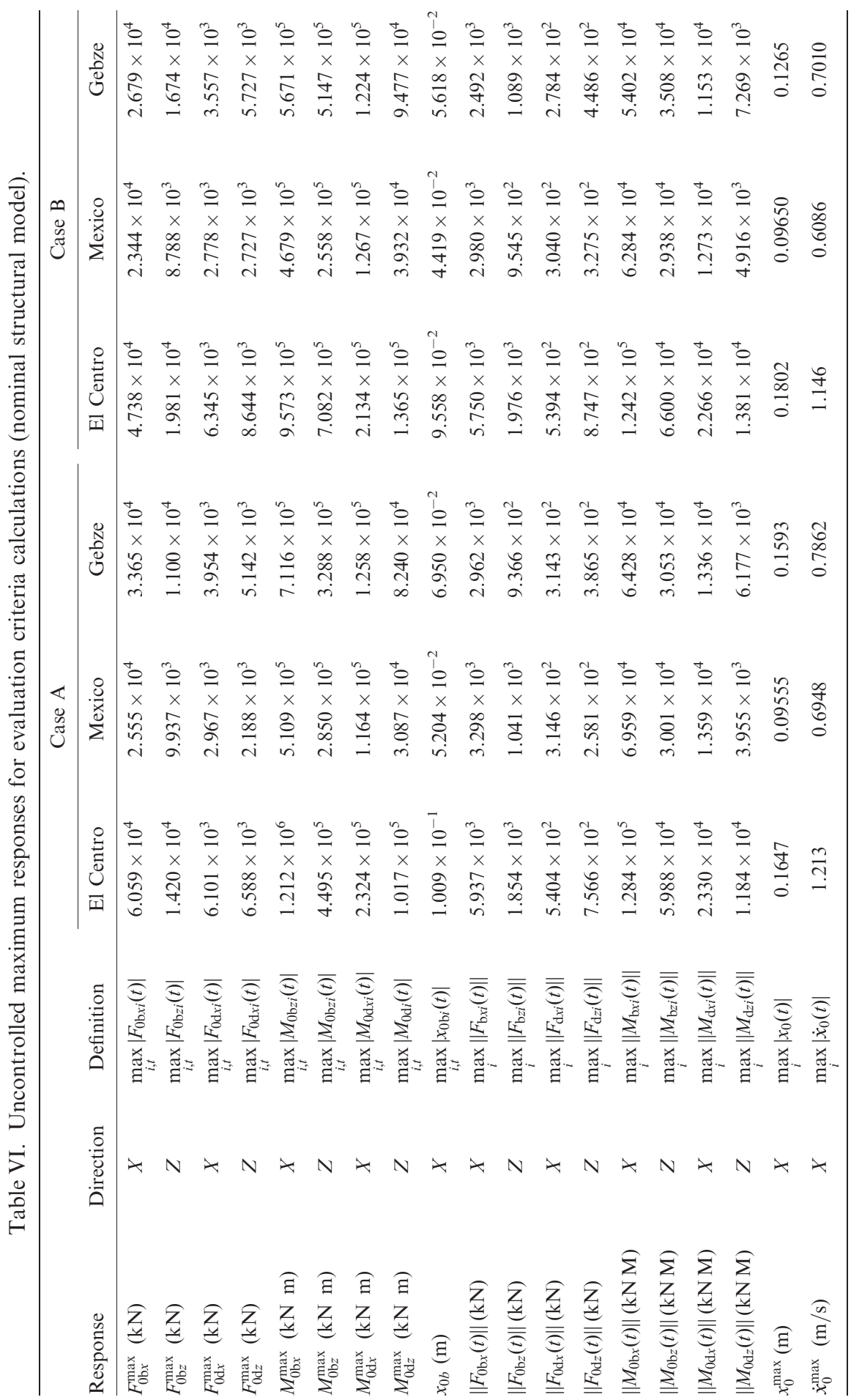




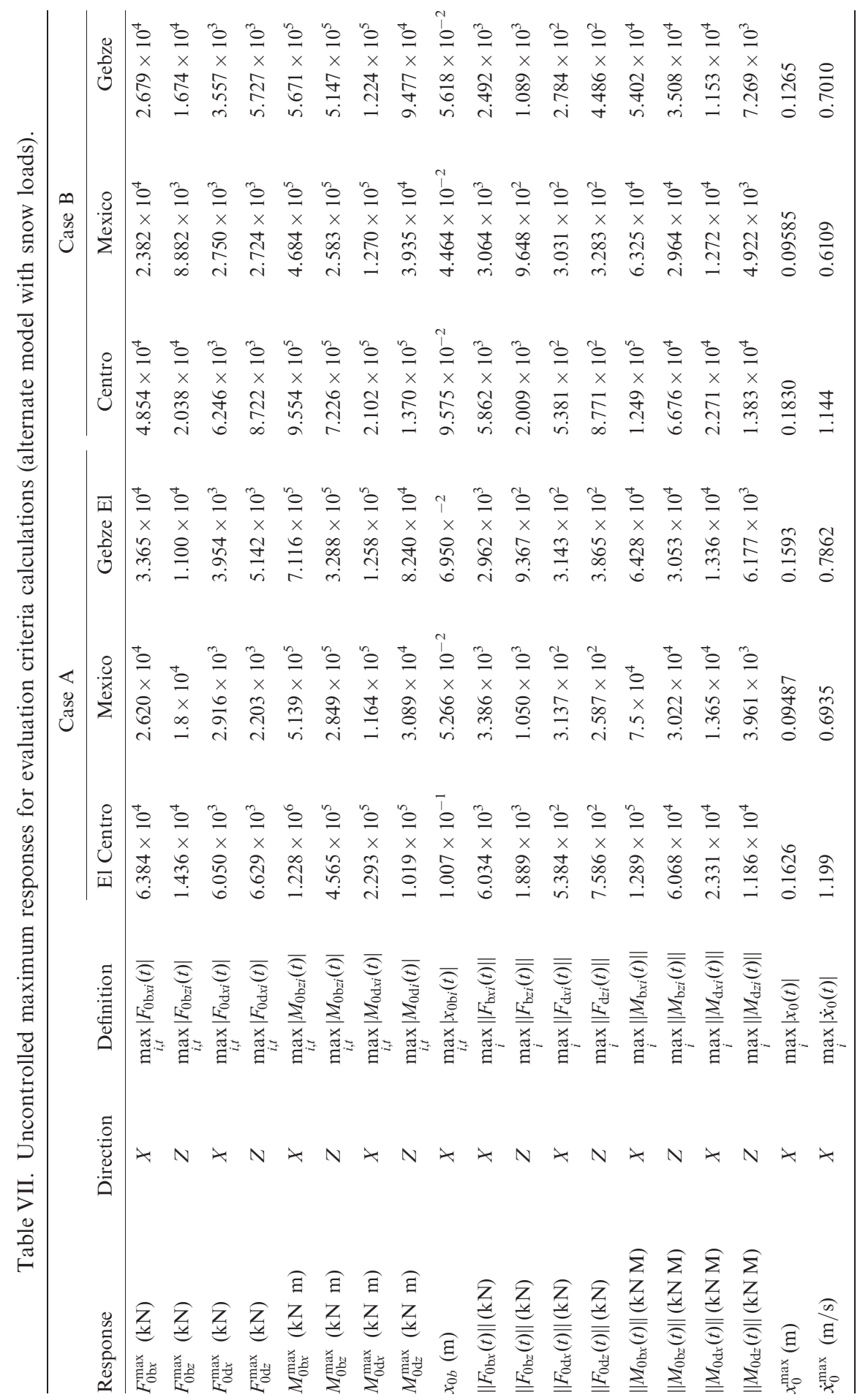




\section{ACKNOWLEDGEMENTS}

This research is supported in part by the National Science Foundation Grant CMS 97-33272 (Dr S.C. Liu, Program Director). The authors would like to thank Mr Shyam Gupta of the Missouri Department of Transportation and Mr Bill Strossener from FHWA for pertinent information on the Cape Girardeau Bridge. The helpful advice of Professor Yozo Fujino (University of Tokyo), Professor Masato Abe (University of Tokyo), Professor Hirokazu Iemura (Kyoto University), Professor Joel Conte (University of California, Los Angeles), Professor Petros Voulgaris (University of Illinois), Professor Fabio Biondini (Politecnico di Milano), and Gerry Pollok (ABAQUS), as well as additional comments provided by members of the ASCE/IASC Task Group on Benchmark Structural Control Problems and other members of the structural control community, are gratefully acknowledged.

\section{REFERENCES}

1. Dyke SJ, Caicedo JM, Turan G, Bergman LA, Hague S. Phase I benchmark control problem for seismic response of cable-stayed bridges. Journal of Structural Engineering 2003; 129(7):857-872.

2. Dyke SJ, Turan G, Caicedo JM, Bergman LA, Hague S. Benchmark control problem for seismic response of cablestayed bridges. Proceedings of the 2nd European Conference on Structural Control, Paris, 3-6 July 2000.

3. Agrawal A, Yang JN, He WL. Performance evaluation of some semi-active control systems for benchmark cablestayed bridge. Proceedings of the 3rd World Conference on Structural Control, Como, 7-11 April 2002; Vol. 2; $863-868$.

4. Turan G, Voulgaris P, Bergman LA. $\mu$-Synthesis control of a cable-stayed bridge against seismic excitation. Proceedings of the 3rd World Conference on Structural Control, Como, 7-11 April 2002; Vol. 2; 857-862.

5. Moon SJ, Dyke SJ, Caicedo JM, Bergman LA, Turan G, Hague S. Phase II benchmark control problem on cablestayed bridges. Proceedings of the 3rd World Conference on Structural Control, Como, 7-11 April 2002; Vol. 2; 849-855.

6. Bakule L, Paulet-Crainiceanu F, Rodellar J, Rossell J. Decentralized overlapping control design for a cable-stayed bridge benchmark. Proceedings of the 3rd World Conference on Structural Control, Como, 7-11 April 2002; Vol. 2; 869-874.

7. Chopra AK. Dynamics of Structures: Theory and Applications to Earthquake Engineering, Prentice Hall; Upper Saddle River, New Jersey, 351-355.

8. Clough RW, Penzien J. Dynamics of Structures; 2nd edn, McGraw-Hill; New York, 1993.

9. Hague S. Composite design for long span bridges. Proceedings of the 15th ASCE Structures Congress, Portland, Oregon, 1997; 51-55.

10. Celebi M. Seismic instrumentation of the Cape Girardeau (MO) cable-stayed bridge. Proceedings of the MidAmerica Seismic Highway Conference, Saint Louis, 28 February-3 March 1999.

11. MATLAB. The Math Works, Inc., Natick, Massachusetts, 1997.

12. Wilson J, Gravelle W. Modelling of a cable-stayed bridge for dynamic analysis. Earthquake Engineering and Structural Dynamics 1991; 20:707-721.

13. ABAQUS. Hibbitt, Karlsson \& Sorensen Inc., Pawtucket, RI, 1998.

14. Ernst HJ. Der E-Modul von Seilen unter Berucksichtigung des Durchhanges. Der Bauingenieur 1965; 40(2):52-55.

15. Caicedo JM, Dyke SJ, Turan G, Bergman LA. Comparison of modeling techniques for dynamic analysis of a cablestayed bridge. Proceedings of the Engineering Mechanics Conference, ASCE, Austin, 21-23 May 2000.

16. Uniform Building Code. International Conference of Building Officials, Whittier, California, 1991.

17. Ohtori Y, Spencer BF. A MATLAB-based tool for nonlinear structural analysis. Proceedings of the 13th Engineering Mechanics Conference, Baltimore, 13-16 June 1999.

18. Spencer BF, Dyke SJ, Deoskar HS. Benchmark problems in structural control-part I: active mass driver system-part II: active tendon system. Earthquake Engineering and Structural Dynamics 1998; 27:1127-1147.

19. Spencer BF, Christenson RE, Dyke SJ. Next generation benchmark control problem for seismically excited buildings. Proceedings of the 2nd World Conference on Structural Control, Kyoto, 29 June-2 July 1998; 1351-1360.

20. Stengel RF. Stochastic Optimal Control: Theory and Application. Wiley: New York, 1986.

21. Skelton RE. Dynamic Systems Control: Linear Systems Analysis and Synthesis. Wiley: New York, 1988.

22. Antoniou A. Digital Filters: Analysis, Design, and Applications. McGraw-Hill: New York, 1993; 444-446. 